\title{
Growth Stages and Hexagonal-Rhombohedral Structural Arrangements in Spheroidal Graphite Observed in Ductile Iron
}

\author{
J. Qing*, V. L. Richards, and D. C. Van Aken \\ Department of Materials Science \& Engineering, Missouri University of Science \& \\ Technology, Rolla, Missouri 65409, USA
}

\begin{abstract}
Crystallographic structures of spheroidal graphite particles (graphite nodules) were examined using transmission electron microscopy (TEM). Structures of graphite nodules were investigated relative to different stages of nodule growth in ductile iron. Curved graphene layers were observed during the early growth of the graphite nodules. Thin layered stacking faults give rise to streaking in the basal reflections, which give rise to curvature of the nodule and growth steps on the surface. Columnar substructures consisting of parallel peripheral subgrains were found in the outside region of graphite nodules that were formed during the intermediate growth stage. Straight planar graphene layers were observed in the columnar substructures. Crystallographic orientation of graphite showed little change through the subgrain and the $c$-axes of multiple subgrains in a single columnar substructure were parallel. A method for characterizing the crystal structures of graphite based on the selected area diffraction pattern was introduced. Both hexagonal structure and rhombohedral structure were found in the spheroidal graphite particles. Possible crystallographic defects associated with hexagonal-rhombohedral structure transition were discussed.
\end{abstract}

\section{INTRODUCTION}

The authors have previously reported on quenching experiments where an inoculated liquid ductile iron was examined at various stages of solidification. [1-3]. It was shown that the size of a graphite nodule reflects its growth stage [1-3]. A graphite nodule with a diameter less than ten microns is in contact with liquid phase and regarded as being retained at an early growth stage [1-2]. Smooth surfaces with circumferentially grown steps were observed in the nodules at early growth stages, and an example of a graphite nodule (seven microns diameter) at early growth stage is shown in Fig 1(a). A growth step observed on the surface of the graphite nodule is highlighted by arrow in Fig. 1(a).

Corresponding author. Tel: 573-341-7886. E-mail: jq4g5@mst.edu (Jingjing Qing) 
The growth step is made of a stack of graphite basal planes (graphene layers) and its growth front is normally bound by graphite prismatic plane.

At later stages of nodule growth the graphene layers are divided into conical structures with open volume defects between the conical portions. An example of a graphite nodule exhibiting a conical structure is shown in Fig. 1(b). Growth steps appear to form by ledge nucleation and spread along the nodule surface until terminated at the open volume defects between the conical portions [2-3]. In both early and later stages of nodule growth, the nodule grows by the addition of graphene layers such that the net growth direction for the nodule is along the basal normal direction (c-direction) [2-3].

The internal structure of spheroidal graphite particles depends upon the growth morphology [4] or the stage of growth [2-3]. Initially, the particle curvature is accommodated by defects in the graphene layers, although this aspect is not wellunderstood. A conical morphology appears at later stages of growth and contains a complex crystallographic substructure [2-3]. Furthermore, structure evolution of the graphite nodule has never been investigated relative to its growth stages. The objective of this study is to understand the crystal structures in graphite nodules relative to the observed growth morphology.

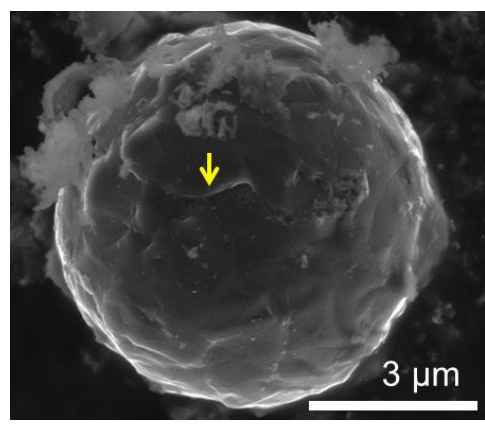

(a)

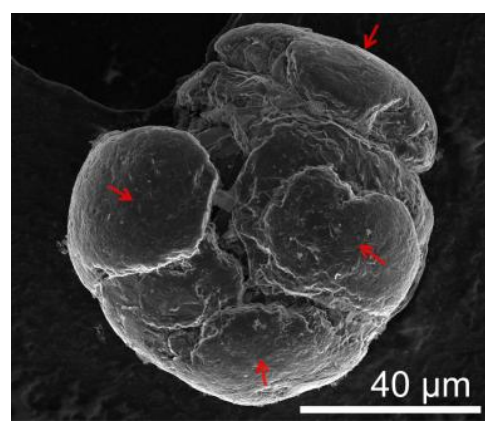

(b)

Fig. 1. Secondary electron image of a graphite nodule at early growth stage (a), and a graphite nodule retained at intermediate growth stage (b). Conical structures were indicated by red arrows in (b).

\section{CRYSTALLOGRAPHIC STRUCTURES OF GRAPHITE}

Crystalline graphite consists of a series of parallel graphene sheets (each plane is considered a basal plane) separated by a distance of 0.33 to $0.36 \mathrm{~nm}$. The carbon atoms 
are bonded by sp2-hybridized bonds within the basal plane and produce three-fold symmetry. An intraplanar sp2-hybridized bond (bonding energy is $524 \mathrm{~kJ} / \mathrm{mol}$ ) is much stronger than an interplanar Pi bond (bonding energy is $7 \mathrm{~kJ} / \mathrm{mole}$ ) between the carbon atoms in the adjacent basal planes [5]. The weaker Pi bond may account for variation of basal plane stacking sequences in the graphite. The crystal structures of graphite vary according to the different basal plane stacking sequences, which include the AAhexagonal structure, the $\mathrm{AB}$ - hexagonal structure and the $\mathrm{ABC}$-rhombohedral structure. An AA-hexagonal structure is thought to be energetically unstable and is unlikely to be present in the natural graphite, but the AA-hexagonal structure was reported to be possible in synthetic Li intercalated graphite [6]. Experimentally observed crystal structures in graphite are commonly the AB-hexagonal 2H structure (space group 194) and the ABC-rhombohedral 3R structure (space group 186) [5]. Schematics for carbon atom arrangements in the $2 \mathrm{H}$ graphite and in the $3 \mathrm{R}$ graphite are shown in Fig. 2(a)-(f): as normal to the (0001) basal plane, the (10T0) prismatic plane, and the (T2T0) prismatic plane.

In this paper, a similar coordinate system is chosen for the $2 \mathrm{H}$ graphite and the $3 \mathrm{R}$ graphite: the in-basal-plane unit vectors are $\overrightarrow{a_{1}}, \overrightarrow{a_{2}}$ and $\overrightarrow{a_{3}}$, of direction [2T10[, [T2T0], and [1120], respectively, and each has a length equal to the hexagon width, as shown in Fig. 2(a) and (d); the $c$-axis ([0001]) is along the nor mal direction to the basal planes. Analyses in this paper assumed the same lattice parameters for a $2 \mathrm{H}$ graphite and a $3 \mathrm{R}$ graphite: (1) the hexagon width $a$ equals $0.246 \mathrm{~nm}$ and (2) the basal plane spacing $c_{0}$ equals $0.335 \mathrm{~nm}$ [7-8]. It should be noted that the $c$-spacing of different graphite structures vary based on the periodicity along the $c$-axis. The minimum distance of repeated basal planes is equal to $2 c_{0}$ or $0.6710 \mathrm{~nm}$ in a $2 \mathrm{H}$ structure and the $c$-spacing is equal to $3 c_{0}$ or $1.006 \mathrm{~nm}$ in a $3 \mathrm{R}$ structure. The $\mathrm{A}, \mathrm{B}$ and $\mathrm{C}$ positions relative to the stacking sequence of the graphite lattice are linked by a translation vector equal to $\frac{1}{3} a<10 \mathrm{~T} 0>$ in this coordinate system. For example, an A-position changes to a B-position by translating the lattice for a $\frac{1}{3} a<10 \mathrm{~T} 0>$ vector, and a B-position is translated to a $\mathrm{C}$ position by the same vector. It also should be noted that variants for $\langle 10 \mathrm{~T} l\rangle$ ( $l$ is integer) prismatic $(l=0) /$ pyramidal $(l \neq 0)$ planes for the $2 \mathrm{H}$ graphite are different from those for the 3R graphite, as schematically illustrated in Fig. 1(c) and (f). Thus, selected area 


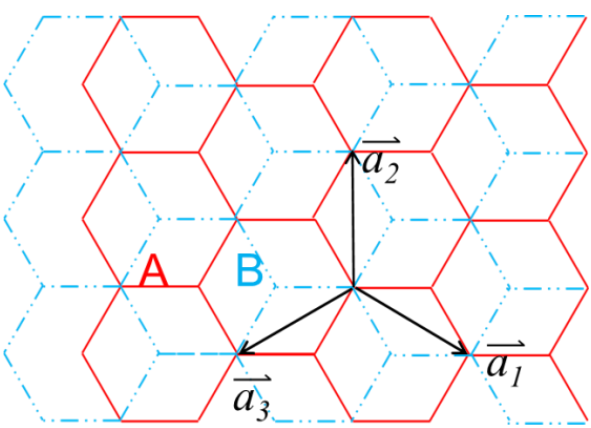

(a)

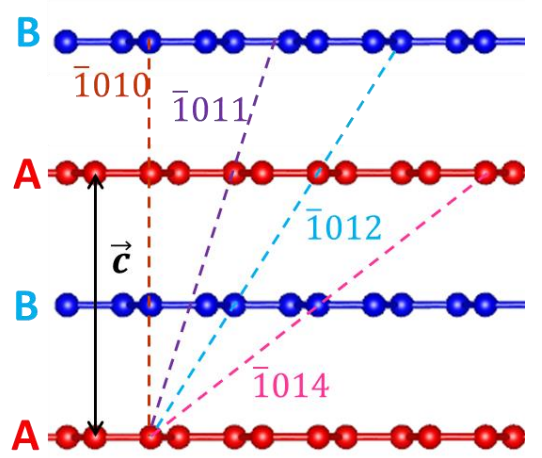

(c)
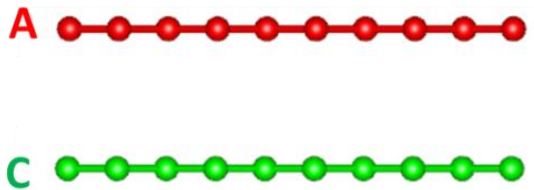

B
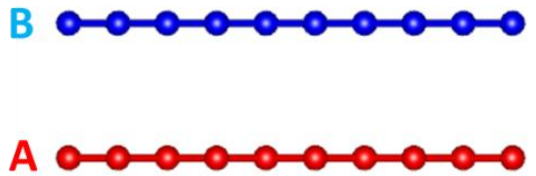

(e)
B
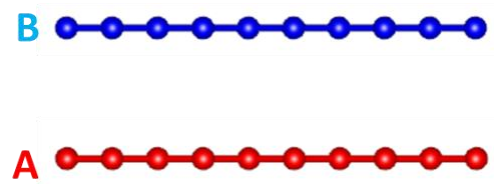

B

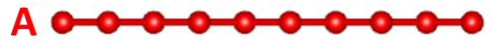

(b)

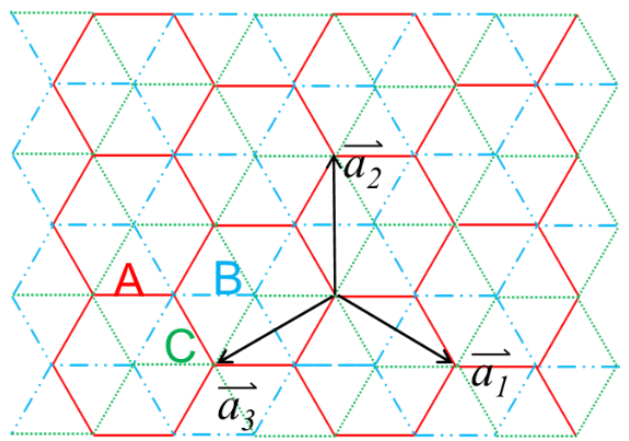

(d)

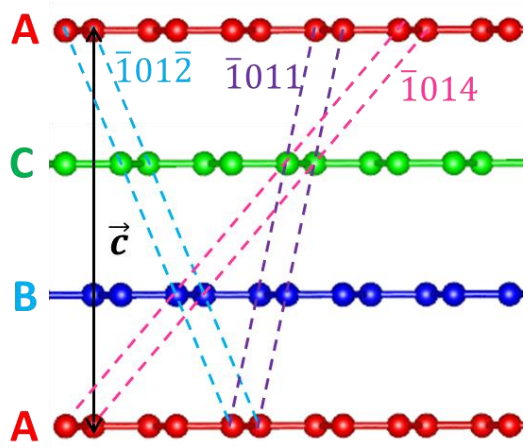

(f)

Fig. 2. Schematics for atom arrangements in the $2 \mathrm{H}$ graphite (a,b and c) and in the 3R graphite (d,e and f). (a) and (d) are viewed along the <0001> directions; (b) and (e) are viewed along the $<10$ T0 $>$ directions; (c) and (f) are viewed along the $<$ T2T0>directions. A coordinate system is defined by the unit vectors, $\overrightarrow{a_{1}}, \overrightarrow{a_{2}}$ and $\vec{c}$ : $\overrightarrow{a_{1}}=\frac{1}{3} a$ [2T10] and $\overrightarrow{a_{2}}=\frac{1}{3} a\langle\mathrm{~T} 2 \mathrm{~T} 0\rangle$, and $\vec{c}=c$ [0001]. $\overrightarrow{a_{3}}=\frac{1}{3} a$ [1120]. $c$ equals $0.6710 \mathrm{~nm}$ in a $2 \mathrm{H}$ structure, and $c$ equals $1.006 \mathrm{~nm}$ in a $3 \mathrm{R}$ structure. (c) and (f) schematically illustrate the $<10 \mathrm{Tl} l>$ planes in a AB-hexagonal graphite and a ABCrhombohedral graphite, respectively. The circles do not represent actual atom size, and the line connecting two atoms does not represent the actual bond length between atoms. 
diffraction patterns for $\mathrm{B}$ (beam direction) $=<\mathrm{T} 2 \mathrm{~T} 0>$ are different for the $2 \mathrm{H}$ graphite and the $3 \mathrm{R}$ graphite and this will be discussed in detail in the following section.

The basal plane stacking sequence for an AB-hexagonal structure $(2 \mathrm{H})$ is known to be the thermodynamically most stable stacking sequence for graphite and is thought to be the only possible structure in natural, pure graphite [5]. The ABC-rhombohedral structure (3R) can be produced by mechanical, chemical, or thermal treatment of natural graphite, and this $3 \mathrm{R}$ structure is separated from the $2 \mathrm{H}$ host by partial dislocations [913]. A $3 \mathrm{R}$ structure is often regarded as a sheared form of the $2 \mathrm{H}$ structure $[9,14]$.

\section{CHARACTERIZING SELECTED AREA ELECTRON DIFFRACTION PATTERNS OF GRAPHITE}

Experimental diffraction patterns obtained using transmission electron microscopy (TEM) convey information about the crystal structure of graphite, i.e. the stacking sequence of the basal planes. Selected area diffraction (SAD) patterns along two prismatic directions, $\langle 10 \mathrm{~T} 0\rangle$ and $\langle\mathrm{T} 2 \mathrm{~T} 0\rangle$, were simulated for different graphite structures using PDF4+ software. It should be noted that only the planes that are parallel to the electron beam and satisfy the constructive interference requirements will produce reflections on the diffraction patterns. The atom arrangements in the $2 \mathrm{H}$ structure and the 3R structure are the same when viewed along the $<10 \mathrm{~T} 0>$ directions (see Fig. 2(b) and (e)), assuming the same $a$ and $c_{0}$ values for the $2 \mathrm{H}$ structure and the $3 \mathrm{R}$ structures. The $3 \mathrm{R}$ can be differentiated from the $2 \mathrm{H}$ structure using zone axis diffraction patterns along the $\langle\mathrm{T} 2 \mathrm{~T} 0\rangle$, whereas $\langle 10 \mathrm{~T} 0\rangle$ zone axis diffraction patterns are identical for the $3 \mathrm{R}$ and 2H structures. Simulated selected area diffraction patterns (SADP) are used to demonstrate the similarities for $\mathrm{B}$ (beam direction) $=<10 \mathrm{~T} 0>$ in Fig. 3 (a) for $2 \mathrm{H}$ and Fig. 3(b) for $3 \mathrm{R}$. In contrast, the $2 \mathrm{H}$ is differentiated from the $3 \mathrm{R}$ by examining the $10 \mathrm{Tl}$ reflections in SADP for $\mathrm{B}=\langle\mathrm{T} 2 \mathrm{~T} 0\rangle$. There are more variants for the $10 \mathrm{~T} l(l=$ integer $)$ pyramidal planes in a $2 \mathrm{H}$ structure that can meet the requirements of the constructive interference than that in the $3 \mathrm{R}$ structure, which produces a greater number of reflections for $\mathrm{B}=<\mathrm{T} 2 \mathrm{~T} 0>\mathrm{SADP}$ for the $2 \mathrm{H}$ structure. Simulated SADP for $\mathrm{B}=<\mathrm{T} 2 \mathrm{~T} 0>$ for $2 \mathrm{H}$ is shown in Fig. 3(c) and 3R is shown in Fig. 3(d). An angle alpha $(\alpha)$ is defined in reciprocal space to differentiate the pyramidal reflection arrangements for the two crystal 
structures. Angle $\alpha$ is formed by connecting the 10T, T01T, and T014 reflections on the $2 \mathrm{H} \mathrm{B}=<\mathrm{T} 2 \mathrm{~T} 0>\mathrm{SADP}$, as demonstrated in Fig. 3(c). Angle $\alpha$ for a 3R $<\mathrm{T} 2 \mathrm{~T} 0>\mathrm{SAD}$ pattern is formed by connecting the $10 \pi$, T012, and T014 reflections, as given in Fig. $3(\mathrm{~d})$. This angle is 90 degrees on the $2 \mathrm{H}<\mathrm{T} 2 \mathrm{~T} 0>$ SAD pattern, and $\sim 84$ degrees (varies depending on the a/c ratio of the structure) on the $3 \mathrm{R}<\mathrm{T} 2 \mathrm{~T} 0>\mathrm{SAD}$ pattern.

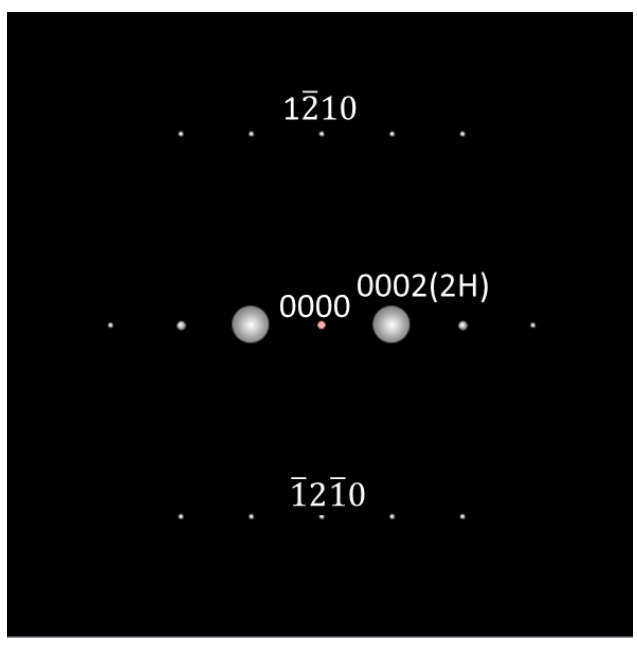

(a)

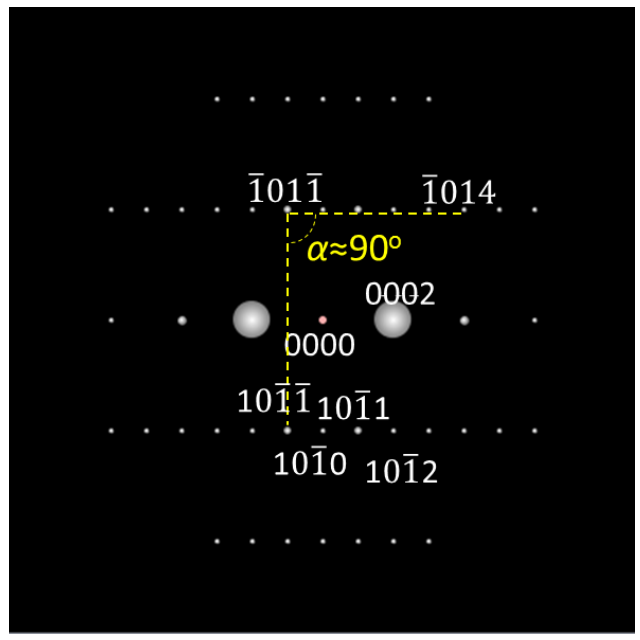

(c)

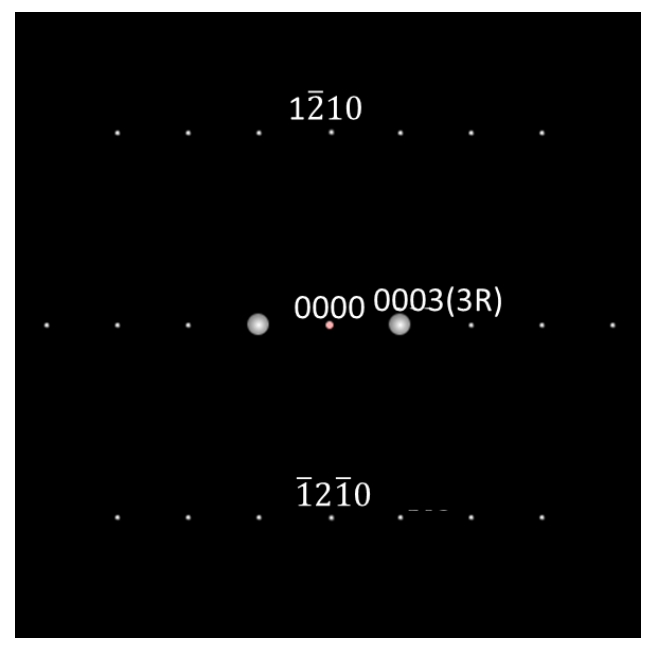

(b)

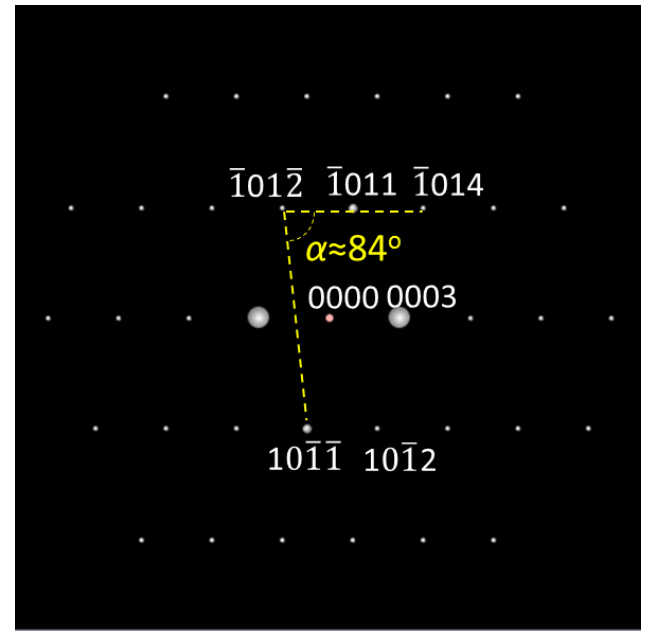

(d)

Fig. 3. Simulated SAD patterns along the $<10 \mathrm{~T} 0>$ zone axes are identical for a ABhexagonal (2H) graphite (a) and a ABC-rhombohedral(3R) graphite (b). Simulated SAD patterns along the $<\mathrm{T} 2 \mathrm{~T} 0>$ zone axes are different for a $2 \mathrm{H}$ graphite $(\mathrm{c})$ and a $3 \mathrm{R}$ graphite (d). Angle $\alpha$ is 90 degrees for the AB-hexagonal structure and approximately 84 degrees for the $\mathrm{ABC}$-rhombohedral structure. The diameters of the spots do not represent the relative intensity of reflections. 
As regard to different variants for the $\{10 \mathrm{Tl}\}$ prismatic/ pyramidal planes in the $2 \mathrm{H}$ and the $3 \mathrm{R}$ structures, not only were more numerous reflections observed on the SAD patterns along the $<\mathrm{T} 2 \mathrm{~T} 0>$ axes of a $2 \mathrm{H}$ structure, but the arrangements of pyramidal reflections (compare Fig. 3(c) to (d)) on different $<$ T2T0> SAD patterns were different for the two structures.

\section{TEM SPECIMEN PREPARATIONS}

The TEM specimens (80-100 nm thick) were cut and thinned using a Helios Nanolab 600 FIB (focused ion beam) system. Graphite nodules observed in ductile irons are not perfectly spherical, especially for the nodules at early growth stages. Statistical measurements on the aspect ratio (long axis vs. short axis ratio) of graphite nodules formed during early growth stages indicated that these graphite nodules tended to be prolate in shape [1-2]. Anisotropic carbon activity surrounding a spheroidal graphite particle may account for the anisotropic growth of small graphite nodules formed during early growth stages [1-2]. The long axis of a spheroidal graphite particle was used as the nodule diameter in this study.

A thin foil TEM specimen was prepared from a spheroidal graphite particle (see Fig. 4(a)) of approximately three-micron diameter from work reported previously [3]. This graphite nodule was from a hypereutectic composition where graphite is expected to form in the liquid and prior to complete encapsulation by austenite, i.e. early growth stage. Similarly, another thin foil TEM specimen was prepared from a spheroidal graphite particle of approximately $30 \mu \mathrm{m}$ diameter, which had been fully engulfed in austenite (see Fig. 4(c)). An absence of eutectic carbide near the graphite surface shows that this graphite nodule was completely surrounded by austenite phase prior to quenching. Fig. 4(b) and Fig. 4(d) show the positions for taking the TEM specimens relative to the spheroidal graphite particles. The thin specimens were cut free from the matrix, and transferred and attached onto copper grids, and they were further thinned down (using the FIB) to an appropriate thickness for viewing using a TECNAI F20 transmission electron microscope (TEM). The acceleration voltage and the emission current for the TEM examinations were $200 \mathrm{kV}$ and $80 \mu \mathrm{A}$, respectively. 


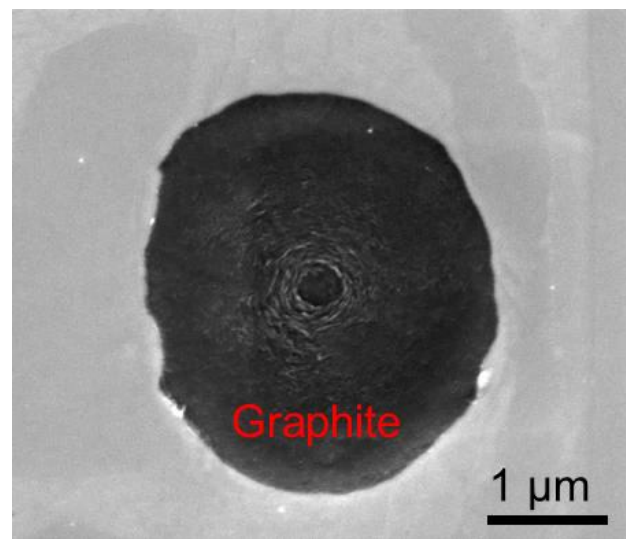

(a)

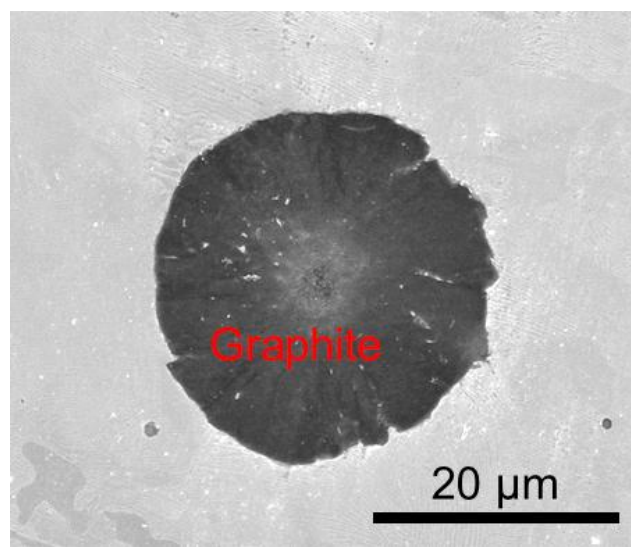

(c)

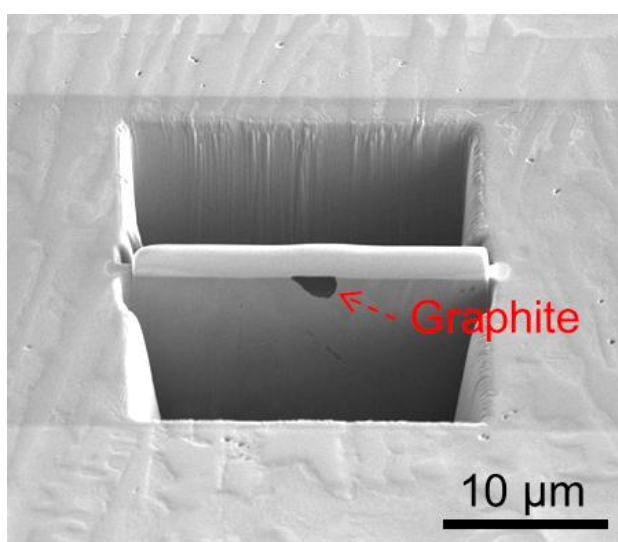

(b)

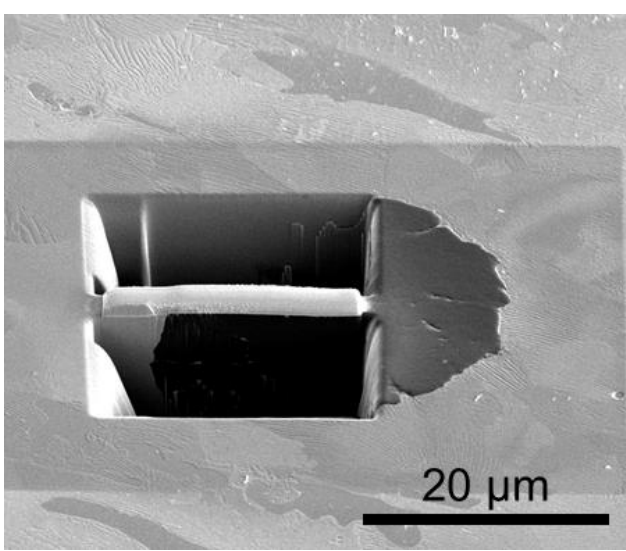

(d)

Fig. 4. (a) Secondary electron image of a three-micron diameter spheroidal graphite particle at early stage of growth. A thin Pt rib was deposited prior to ion milling to protect the graphite edge. (b) A thin section was machined from (a) using the FIB. (c)

Secondary electron image of a $30 \mu \mathrm{m}$ diameter spheroidal graphite particle at intermediate stage of growth. (d) A thin section was machined from (c) using the FIB.

\section{TEM RESULTS}

\subsection{Graphite Structures at Early Growth Stages}

Fig. 5(a) is a bright field TEM image of the specimen prepared from the graphite particle retained at its early growth stages. A SADP with $B=<T 2 T 0>$ obtained from the highlighted area in Fig. 5(a) is shown in Fig. 5(b). The aperture size chosen for the SAD pattern was $150 \mathrm{~nm}$ in diameter. Basal plane spacing determined on Fig. 5(b) is approximately $0.348 \mathrm{~nm}$. It can be seen that the diffraction patterns consist of multiple structures with slightly varying orientation for each in Fig. 5(b); specifically, the basal 
planes were tilted at small angles (the largest angle was less than nine degrees) from each other, i.e., the normal of the basal plane gradually changed for about nine degrees in the selected area. This observation was repeated throughout the investigation of this nodule indicating that the basal plane orientations continuously and gradually changed in the graphite formed during the early growth stages. However, differentiation between $2 \mathrm{H}$ and $3 \mathrm{R}$ was not possible from SAD patterns obtained.

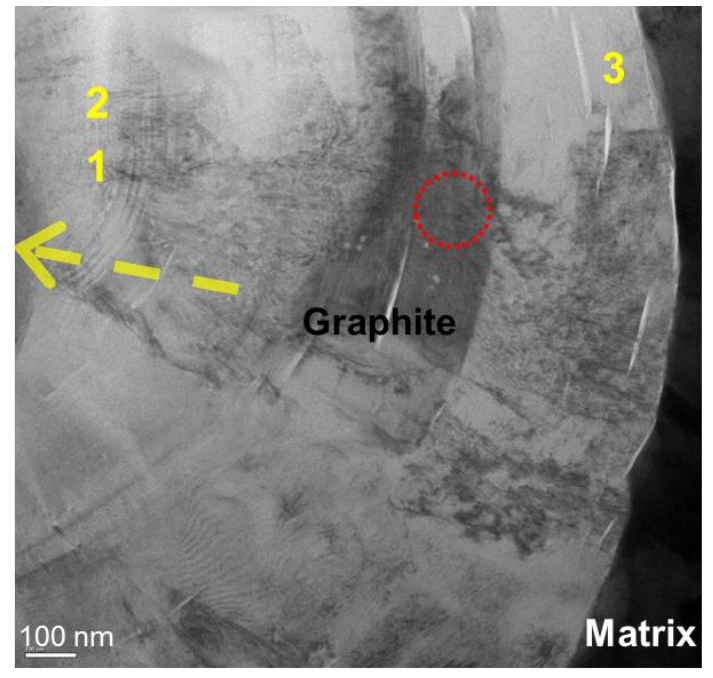

(a)

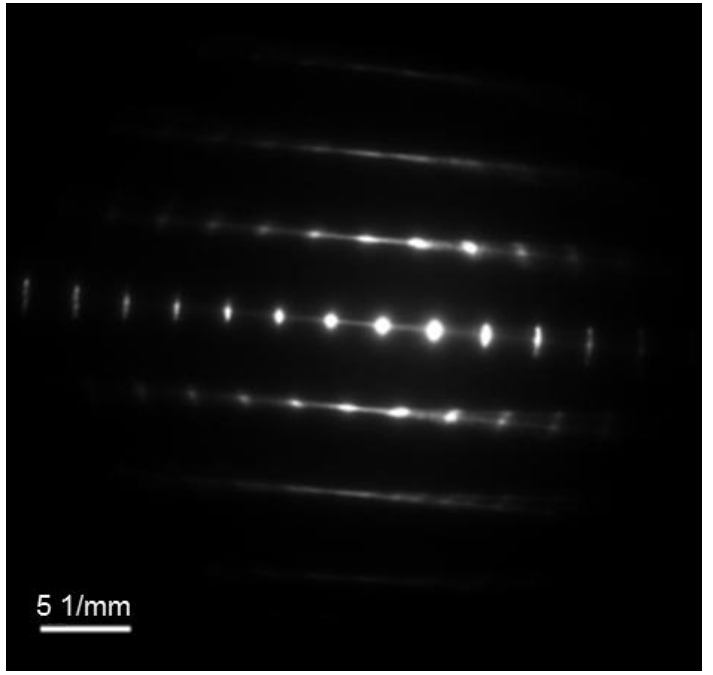

(b)

Fig. 5. Bright field image of the specimen prepared from a spheroidal graphite particle of three-micron diameter (at early stage of growth). Center of the particle is indicated by dashed arrow in (a). (b) An SAD pattern obtained from the area highlighted by the red dotted circle in (a). Gradually changed basal plane directions led to multiple sets of diffraction patterns tilted at small angle from each other.

A high resolution image of the graphite lattice close to the center of the spheroidal graphite particle in Fig. 5(a) is given in Fig. 6. Basal plane spacing measured on Fig. 6 is $0.358 \mathrm{~nm}$ (average of 300 basal plane spacing). The layered basal planes are evident in the high resolution image. It was observed that the basal planes are curved and their directions change gradually to accommodate the curvature in the spheroidal graphite particle. The basal planes next to the center of the particle are neither perfectly parallel nor straight. Both concave curvature and convex curvature are observed in Fig. 6. This change in the curvature may be the early formation of the columnar structure (details can 
be found in section 5.2), i.e. coherent columnar versus semi-coherent. It was observed that as the graphite nodule grows a loss in coherency occurs and the growth mode becomes competitive between adjacent graphite columns [3]. Defects are frequently observed in the graphite lattice, both near the center (see Fig. 7(a)) and at the surface (see Fig. 7(b)) of the early growth nodule. The defects in the form of "extra half" plane are indicated by the red arrows in Fig. 7. Basal plane spacing measured on Fig. 7(a) is 0.348 $\mathrm{nm}$ and on Fig. 7(b) is $0.347 \mathrm{~nm}$ (each was averaged over 300 basal plane spacing).

Attempts on collecting convergent beam electron diffraction (CBED) patterns from small regions of the graphite were made, but the quality of the CBED pattern was not sufficient for structural characterization. This might be caused by the distortion/curvature in the graphite lattice or by the high density of defects in the graphite lattice.

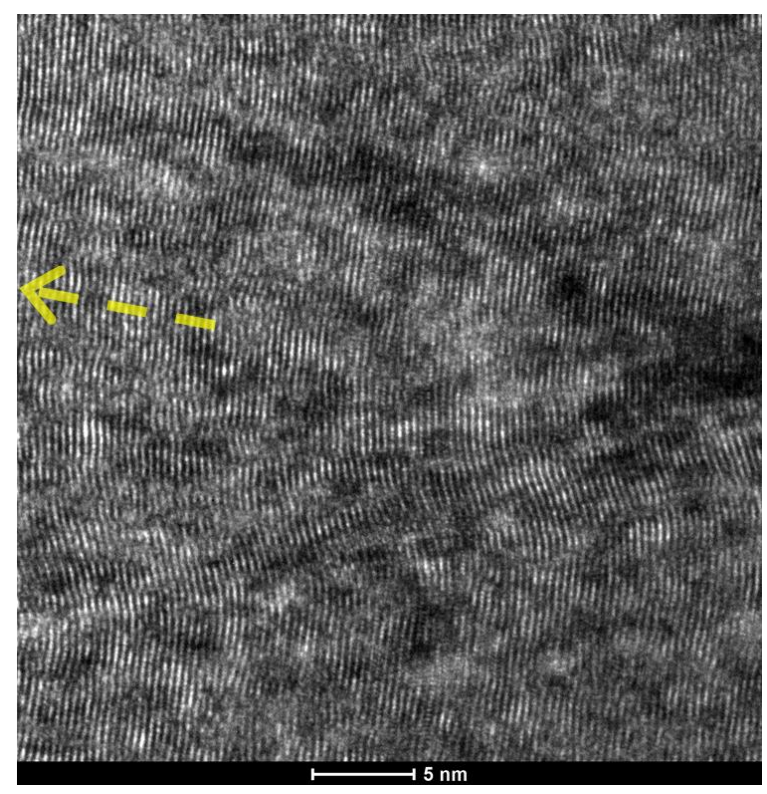

Fig. 6. High resolution image of the graphite lattice near the center of the spheroidal graphite particle at position " 1 " in Fig. 5(a). Center direction of the nodule is indicated by the dashed arrow. Curved basal planes accommodate the curvature of the spheroidal graphite particle. 


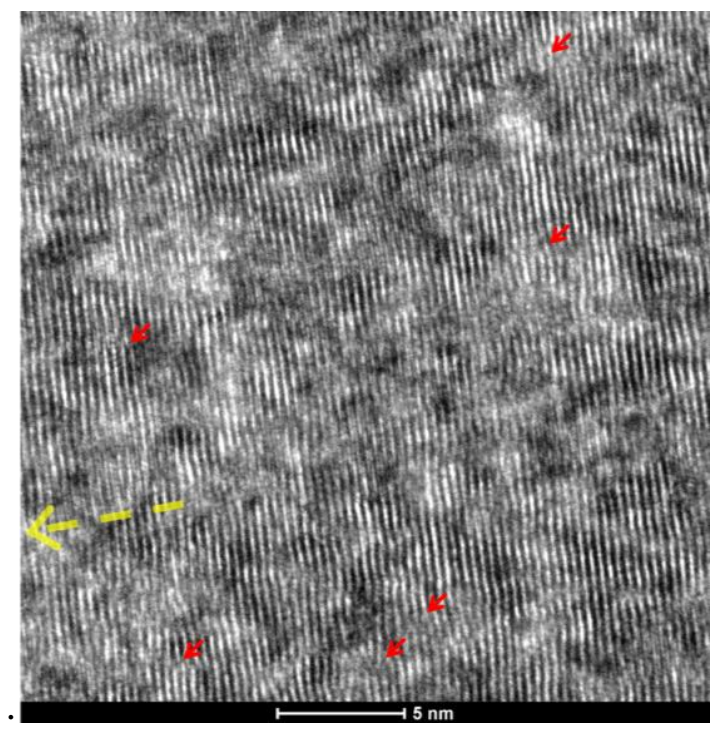

(a)

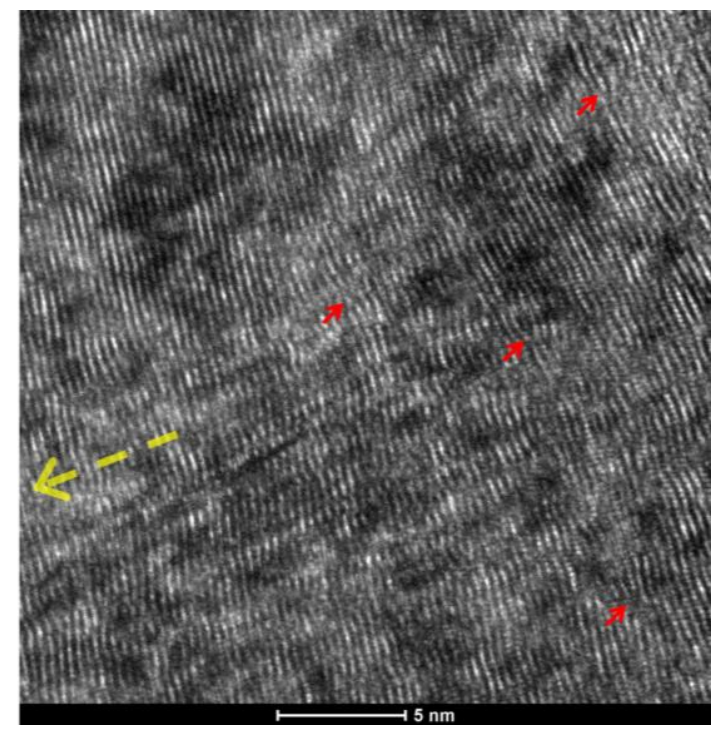

(b)

Fig. 7. High resolution images of the graphite lattice near the center (a) of the graphite particle at position " 2 ", and near the surface (b) of the graphite particle at position "3" in Fig. 5(a). Defects in the form of "extra half" planes are indicated by the red arrows, which may be interpreted as geometrically necessary edge dislocations to produce the observed curvature. Center direction of the nodule is indicated by dashed arrows.

\subsection{Graphite Structures at Intermediate Growth Stages}

Fig. 8(a) is a bright field TEM image of the large graphite nodule from an intermediate growth stage that exhibits a columnar subgrain structure. Fig. 8(b) is a higher magnification image of the specimen near the nodule surface (highlighted by the yellow box in Fig. 8(a)). Columns of crystals separated by radially oriented grain boundaries (examples are highlighted by the red dashed lines in Fig. 8(a)) were observed in the periphery of this graphite nodule. The columnar substructures outlined many radially oriented fan-like areas in the outside area of the graphite nodule. No evidence of the columnar substructure was observed near the center (formed during early growth stages) of the graphite particle. The columnar substructure is also absent in the graphite particle shown in Figs. 5-7. This indicated that the graphite structures might change between its early growth stage and its intermediate growth stage. 


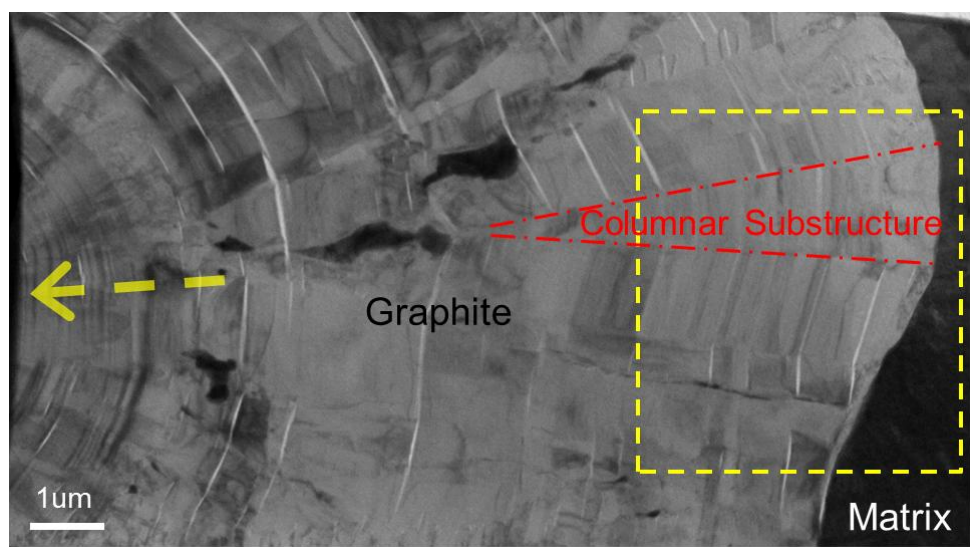

(a)

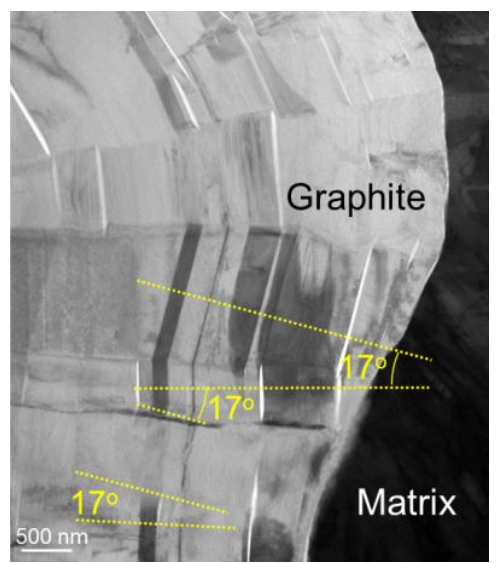

(b)

Fig. 8. Bright field TEM images of the specimen at intermediate stage of growth, with a spheroidal graphite particle, at a lower magnification (a) and a higher magnification (b). Center of the nodule is indicated by the dashed arrow.

Each columnar substructure was found to consist of many crystallites/subgrains (see the highlighted area for an example), appearing as straight blocks at different diffraction contrast in the dark field image in Fig. 9. Subgrains were radially stacked in the columnar substructure. The subgrains aligned in the radial direction of the same columnar substructure have parallel $c$-axes as shown by SAD patterns in Fig. 10. However, their crystallographic orientations are rotated about the c-axis from one subgrain to the next subgrain within the column structure, which implies that there may be $c$-axis rotation faults/twist boundaries between the adjacent subgrains.

Fig. 11 is a high resolution image of the graphite in a subgrain near the matrix (austenite) interface of the nodule. Defects are indicated by the red arrows in Fig. 11. The basal planes appear to be less curved in a subgrain than that in the graphite formed during the early growth stages. Moreover, an SAD pattern obtained in a subgrain (which was formed during intermediate growth stages) showed a single $c$-axis direction, in contrast to the multiple $c$-axis directions on an SAD pattern from the center of graphite particles captured at both early and intermediate growth stages, i.e. all graphite nodules begin with identical structures of spherically curved basal planes. Several SAD patterns collected from one subgrain (obtained in the highlighted areas) are shown in Fig. 12, and it is found that the crystallographic orientation of the graphite is essentially unchanged. 


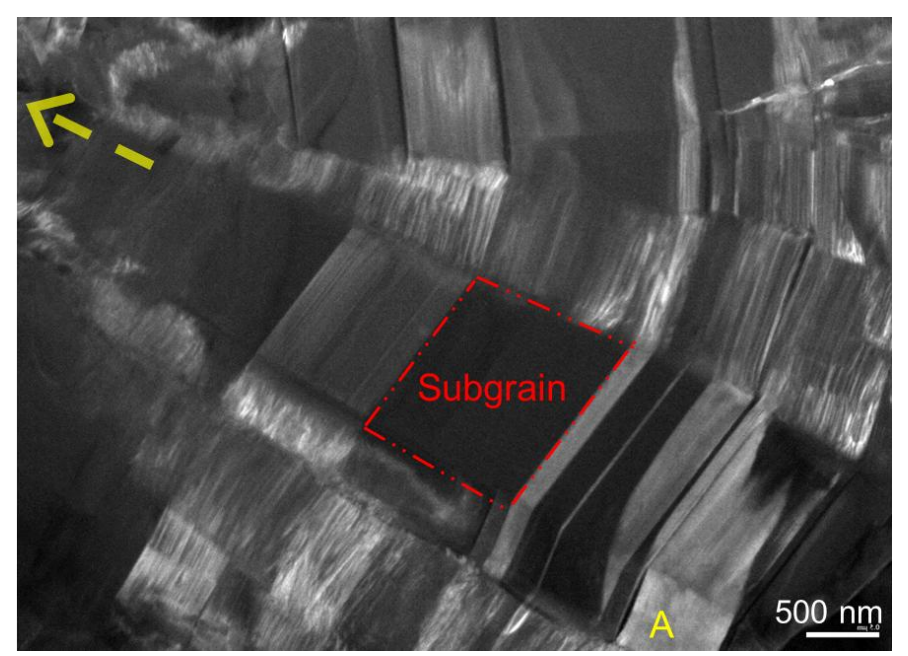

Fig. 9. Dark field image of the graphite particle at intermediate stage of growth. Each columnar substructure is made of many parallel subgrains. An example for a subgrain is highlighted by the red box. Center direction of the nodule is indicated by the dashed arrow. $\overline{1} 011$ plane of grain A was used for dark field imaging.

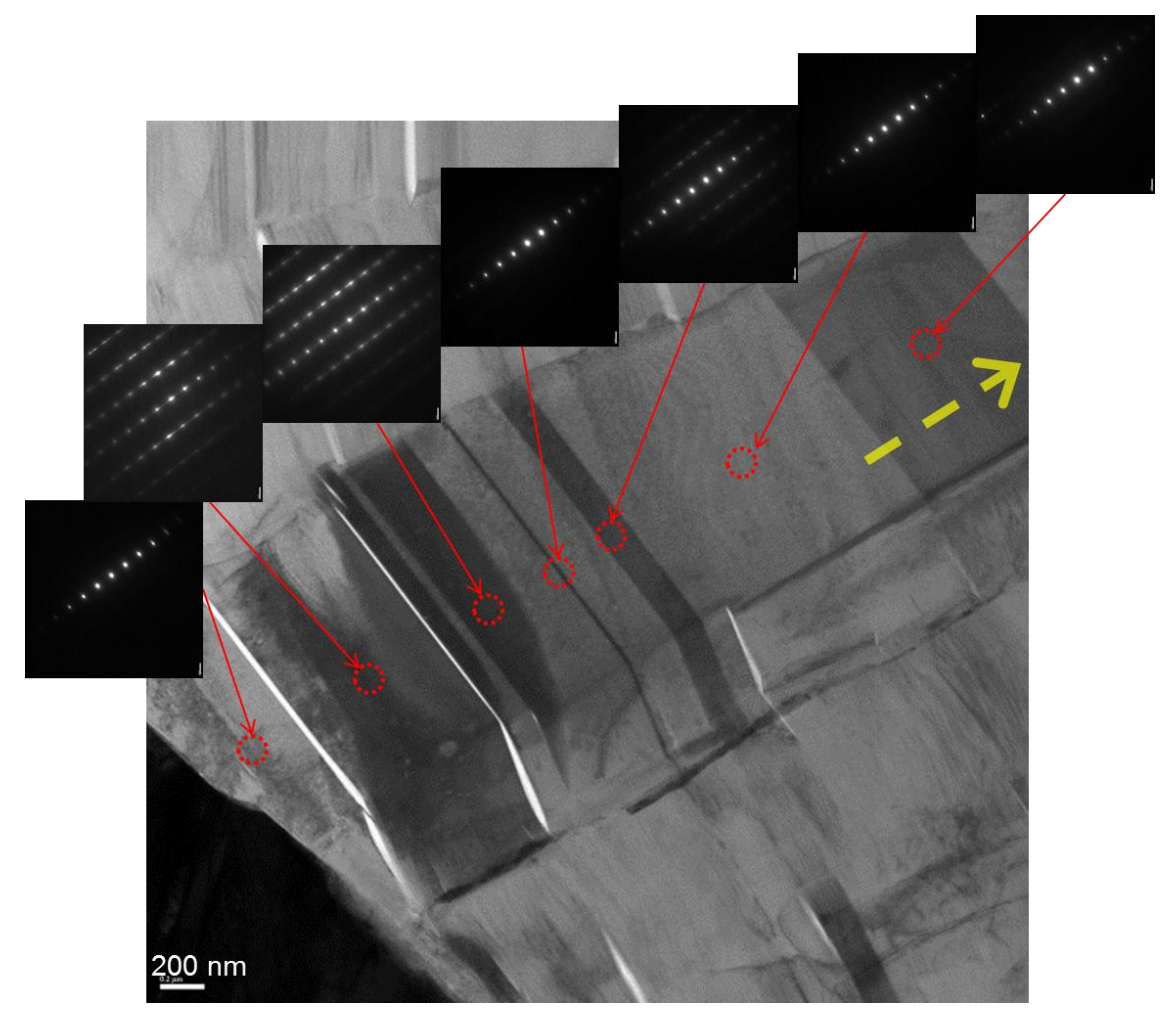

Fig. 10. SADPs (insets) collected in the subgrains in a single graphite column. The $c$-axes of these subgrains are parallel. Center direction of the nodule is indicated by the dashed arrow. 


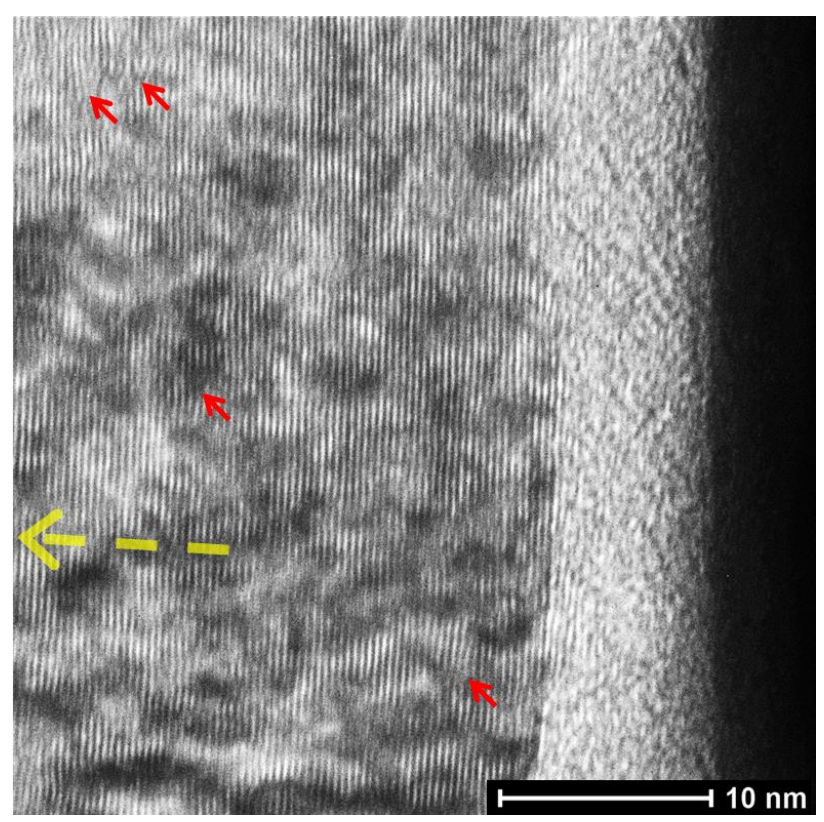

Fig. 11. High resolution image of the graphite in a subgrain at the surface of the spheroidal graphite particle in Fig. 9(a). The dark contrast feature on the right is the iron matrix. There is an amorphous carbon layer between crystalline graphite and matrix. Center direction of the nodule is indicated by dashed arrow.
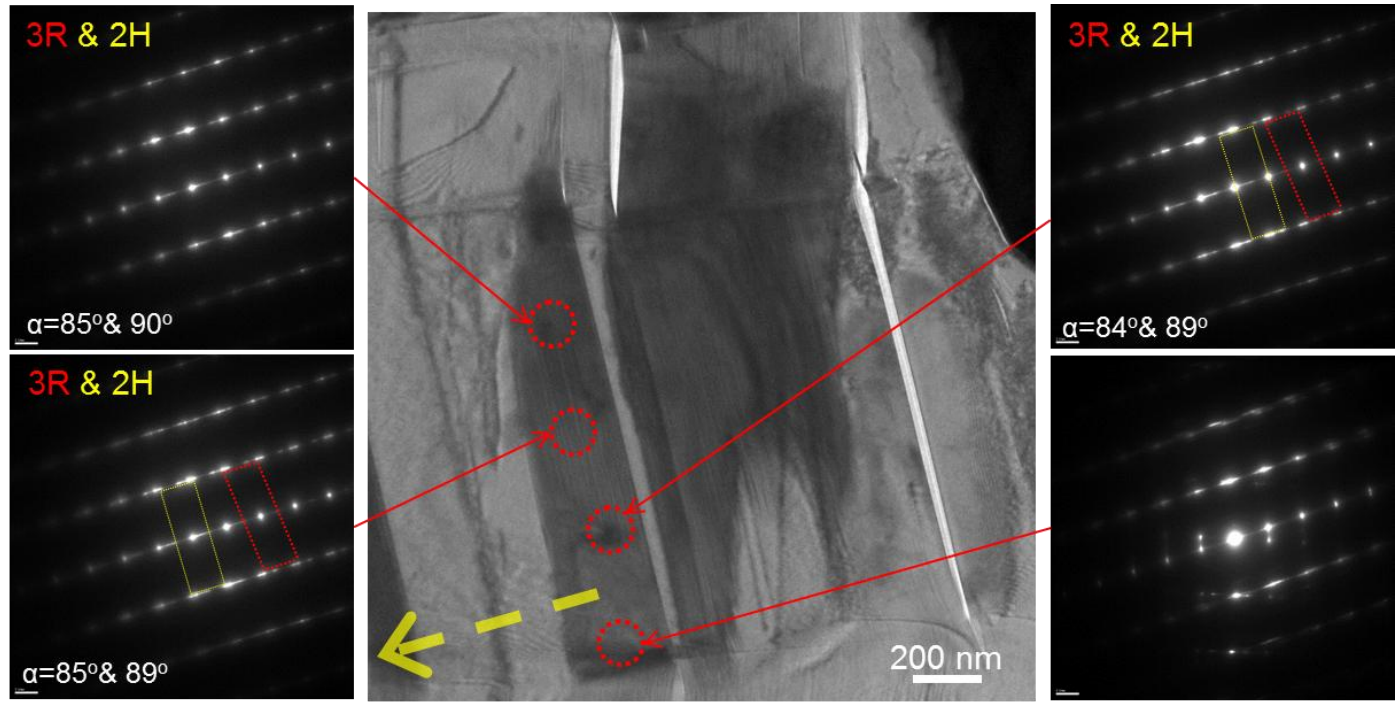

Fig. 12. SAD patterns (insets) obtained in a subgrain from the highlighted area. The crystallographic orientation did not change across this grain. The crystal structures were determined based on the angle $\alpha$ on the SAD patterns for $\mathrm{B}=<\mathrm{T} 2 \mathrm{~T} 0>$. Mixture of $2 \mathrm{H}$ structure and $3 \mathrm{R}$ structure were observed. Center direction of the nodule is indicated by the dashed arrow. 
In contrast to the early growth structure, sharp transitions of the basal plane directions were observed between adjacent columnar substructures at later stages of nodule growth. A high resolution TEM image of a boundary between two columnar substructures is shown in Fig. 13, which shows a $35^{\circ}-40^{\circ}$ angle between basal plane normals for the adjacent columns. Examples of the SADP obtained along a columnar boundary (highlighted by the red dashed circles) are shown in Fig. 14 where both subgrains have a similar beam direction of $\mathrm{B}=\langle\mathrm{T} 2 \mathrm{~T} 0\rangle$. In this example, the columnar boundary can be shown to be a simple tilt boundary of $17^{\circ}$ about a $<\mathrm{T} 2 \mathrm{~T} 0>$ axis. The same 17 -degree tilt angles were also measured for several other pairs of adjacent subgrains across a boundary, as shown in Fig. 8(b).

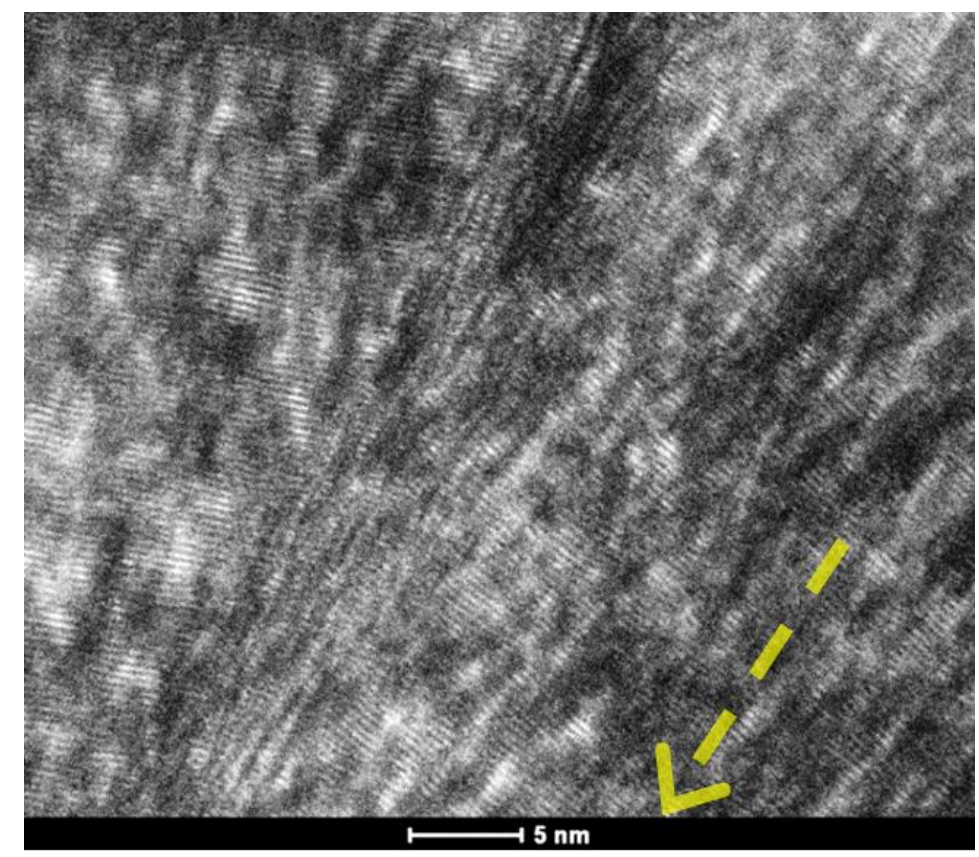

Fig. 13. Tilted basal planes across a boundary between two columnar substructures. The measured tilt angle is in the range of 35-40 degrees. Notice that this boundary plane is not parallel to the beam. Center direction of the nodule is indicated by the dashed arrow. 


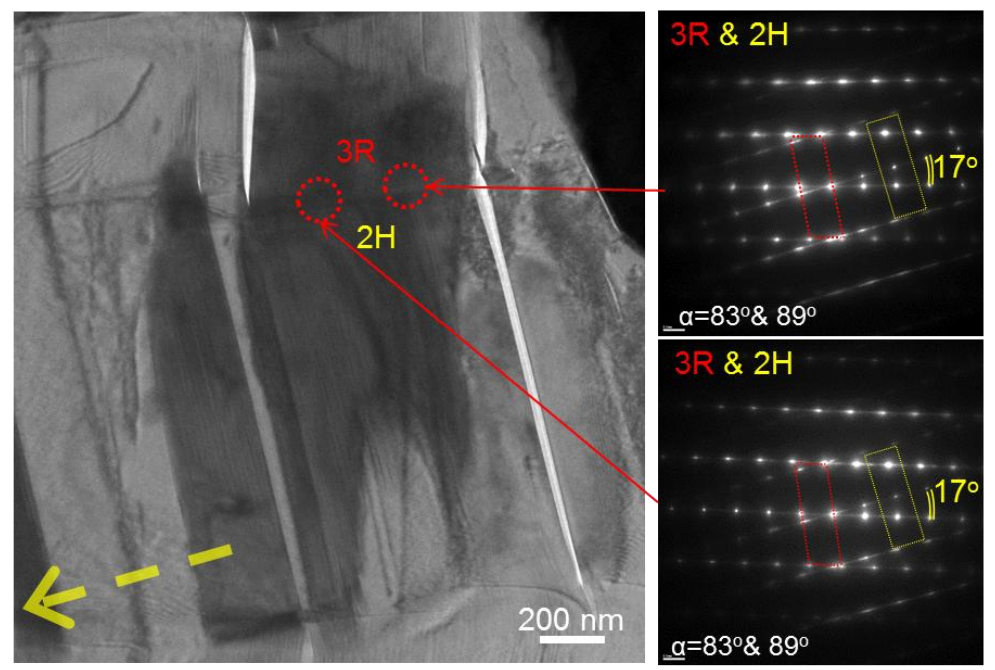

Fig. 14. Basal plane tilt angle between two subgrains from the adjacent columnar substructures were determined to be 17 degrees about the $\langle\mathrm{T} 2 \mathrm{~T} 0\rangle$ axis, based on the

SAD patterns from the highlighted areas (insets). The crystal structures were determined based on the angle $\alpha$ on the SAD patterns. Center direction of the nodule is indicated by the dashed arrow.

\subsection{H and 3R Structure Arrangements}

A more in-depth analysis of the $\mathrm{B}=<\mathrm{T} 2 \mathrm{~T} 0>$ SADPs reveals that the crystal structure of a single subgrain within a graphite column is a mix of both $2 \mathrm{H}$ and $3 \mathrm{R}$ crystal structures as shown in Fig. 12 and the $c$-axes of the two structures were exactly parallel. It has been mentioned earlier in this paper that the angle $\alpha$ measured on a $2 \mathrm{H} \mathrm{B}=<\mathrm{T} 2 \mathrm{~T} 0>\mathrm{SADP}$ equals $90^{\circ}$ whereas $\alpha$ measured on a $3 \mathrm{R} \mathrm{B}=<\mathrm{T} 2 \mathrm{~T} 0>$ SADP is approximately $84^{\circ}$. Considering the errors in measurement, a structure with an $\alpha$ angle smaller than $85^{\circ}$ was regarded as a $3 R$ structure; a structure with the $\alpha$ in the range of $85^{\circ}-89^{\circ}$ was treated as a transition structure which was in between the $2 \mathrm{H}$ structure and the $3 \mathrm{R}$ structure; a structure with the $\alpha$ larger than $89^{\circ}$ was treated as a $2 \mathrm{H}$ structure in this study. The size of the individual $2 \mathrm{H}$ and $3 \mathrm{R}$ domains could not be determined from either high resolution images or using the smallest available SAD aperture of $150 \mathrm{~nm}$. Nevertheless the $2 \mathrm{H}$ and 3R domains were of a size such that intensity from constructive interference was sufficient to produce identifiable diffraction patterns. Streaking was observed in these diffraction patterns and indicated that the domains are thin in the basal direction $(<0001>)$. Again attempts were made at collecting CBED patterns from small-sized 
domains in the specimen but the pattern quality was not sufficient for structural characterization.

The SAD patterns in Fig. 14 were collected at a boundary where a $17^{\circ}<\mathrm{T} 2 \mathrm{~T} 0>$ tilt boundary was observed. Diffraction patterns for both the $2 \mathrm{H}$ and $3 \mathrm{R}$ structures were found in the graphite particle studied. In this example, the crystal structure changed from a predominantly $2 \mathrm{H}$ structure (in the top grain) to a predominantly $3 \mathrm{R}$ structure (in the bottom grain) across the tilt boundary. The structure changed to a mix of the $2 \mathrm{H}$ structure and the $3 \mathrm{R}$ structure again at increasing distance from the tilt boundary into each adjacent subgrain.

\section{DISCUSSION}

\subsection{Growth Stages of Spheroidal Graphite}

Crystallographic structure varies along the radius of spheroidal graphite, implying a growth mechanism transition between growth stages. During the early growth stages of a graphite nodule (after nucleation) when the nodule was in contact with liquid, graphite growth occurred by adding curved graphene layers circumferentially onto the growing nodule. Graphene layers continuously and gradually changed their orientation during the early growth stages to form the nodular shape. In a previous study, multiple growth steps have been observed on the surface of a graphite nodule during the early growth stage and it was suggested that carbon atoms accreted onto these prismatic sites to grow the individual step circumferentially over the surface of the nodule [2-3]. In combination with the TEM observations presented here, it may be concluded that the early growth of a graphite nodule follows a circumferential growth model [15]. Moreover, circumferential growth led to a particle surface without a distinct segmented substructure, thus the graphite nodules at early growth stages had smoother surfaces [2-3].

During the intermediate growth stages when a graphite nodule grew inside a solid austenite shell, graphite growth continued by growing segmented columnar substructures. Multiple growth ledges with prismatic steps exist at the matrix-graphite interface, but are terminated at void defects between the conical segments [2-3]. Tilt boundaries divided each conical structure into multiple columnar substructures. Nodule curvature is a result of these radial tilt boundaries and the segmented conical structure. Occurrence of 
columnar substructures indicated that the graphite growth mechanism during intermediate growth stage is different from that for early growth stage. The basal planes showed sharp orientation change across the boundary between columnar substructures. In this case, mismatch between the independently growing segments would not always be accommodated by tilt boundaries, especially in the larger-sized graphite nodules. As a result, open-volume defects occurred between two growth fronts due to the large mismatch. Peripherally stacked $c$-axis rotation faults produced extra growth steps for carbon accretion, which would allow faster graphite growth than that without rotation fault. Furthermore, $c$-axis rotation faults could decrease graphite lattice mismatches when growth steps are stacked on each other in a nodule. The graphite basal planes appeared to be straight and planar in the region formed during intermediate growth stages of a nodule, where the curvature of the particle was smaller. A schematic illustrating the growth stages of spheroidal graphite is given in Fig. 15. A similar growth model has been reported for the spheroidal graphite from $\mathrm{Ni}-\mathrm{C}$ alloy [16], where radial growth of pillars instead of conical substructures were observed in the graphite particles. Stacking of crystalline graphite blocks upon each other with the c-axis directions parallel to the radial direction of graphite nodule was well documented in the literature [17-20]. Segments and substructures similar to the observations in the present study have been reported by Miao et al. [17-18], Theuwissen et al. [19] and Monchoux et al. [20], where spheroidal graphite particles were examined using TEM [17-20]. Sharp transition on basal plane orientations were not only observed in the present study (see Fig. 13), but Theuwissen's and Monchoux's studies also showed similar high resolution TEM images of tilt boundary/twin boundaries in graphite nodules [19-20]. Previous studies [17-20] have also revealed various defects in the graphite nodules such as tilt boundary, twin boundary, caxis rotation boundary and c-spacing modulation due to impurity atom. However, circumferential growth of curved graphene layers during early stage of growth was not differentiated using TEM in the earlier studies [17-20]. 


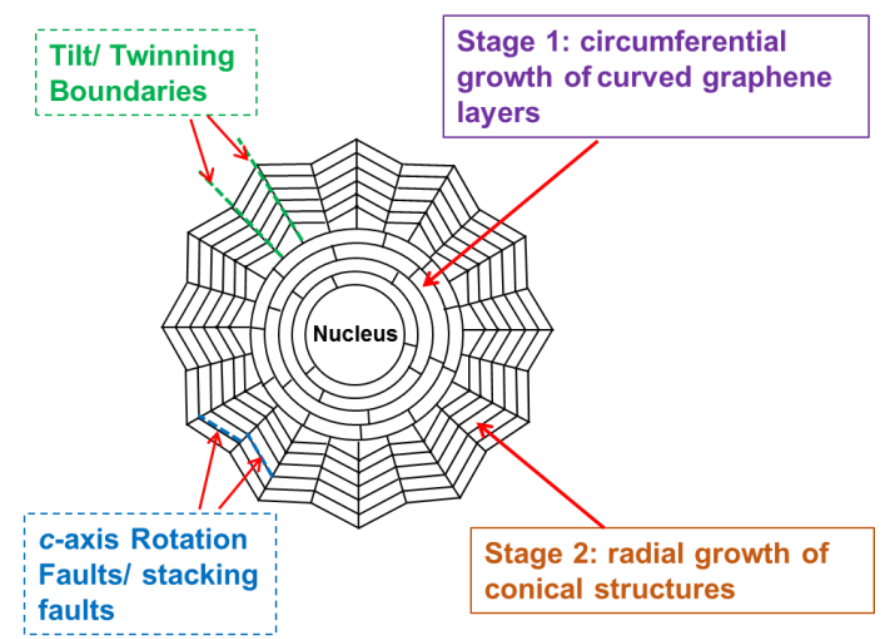

Fig. 15. Schematic for growth stages of spheroidal graphite particle.

\subsection{H and 3R Structures in Spheroidal Graphite}

Mixtures of $2 \mathrm{H}$ structure and 3R structure are present in the spheroidal graphite particles studied, and the two structures share a common $c$-axis direction within a subgrain. Size of the domain with only the $2 \mathrm{H}$ structure or the $3 \mathrm{R}$ structure is too small to be differentiated by either SAD or CBED. Miao et al. observed platelet features (a few microns in size) with the $3 \mathrm{R}$ structure in a graphite nodule from ductile iron, and interplatelet features with $2 \mathrm{H}$ structures were observed in between the platelets [17-18]. No discernable platelet and interplatelets were observed in the specimens from the present study. However, the streaking in graphite SADPs along the basal direction would suggest the presence of thin platelets. The platelet features in the specimens from present study might be too small to differentiate using TEM. Moreover, the orientations of the $2 \mathrm{H}$ structures in this study were always found to be well-defined with the c-axis parallel with the radial growth, in contrast to the random orientations of the $2 \mathrm{H}$ structures in Miao et al.'s study [17-18]. However, this difference may be due to the fact that the graphite particles in the present study are quenched, compared to the unquenched sample in Miao et al.'s study. It is possible that the quenching process may have altered the graphite structure in the present study, which merits further investigation in the future. Based upon the experimental observations of this study, the structure transition between a $2 \mathrm{H}$ structure and a $3 \mathrm{R}$ structure is capable of accommodating the curvature of the nodule while maintaining the basal growth direction. It is also possible that mixtures of $2 \mathrm{H}$ structure and $3 \mathrm{R}$ structure were produced by bending or twisting the basal planes during 
curvature accommodation. The existence of $3 \mathrm{R}$ structure in spheroidal graphite was sometime neglected or not recognized in the previous studies [19-20], which might result from the complexity of differentiating $2 \mathrm{H}$ and $3 \mathrm{R}$ structures.

A perfect $2 \mathrm{H}$ structure with the basal planes stacked in an $\mathrm{ABAB}$... manner will not change to a $3 \mathrm{R}$ structure (of $\mathrm{ABCABC}$... stacking sequence) without the introduction of defects. In the following sections, several possible defects that can either change the crystal structure of graphite or tilt/bend the graphite lattice will be discussed.

\subsection{Dislocations, Partial Dislocations and Twin Boundaries in Graphite}

Dislocations in graphite have been studied in considerable detail [21-26]. A dislocation with its dislocation line and Burger's vector lying in the basal planes is called a basal plane dislocation [21, 25], which is the most prevalently observed dislocation in both natural and synthetic graphite [21]. A total basal dislocation in graphite has a Burger's vector equal to $\frac{1}{3} a<1210>$ [21-22], and Fig. 16 schematically illustrates a total edge dislocation that lies in the basal plane (dislocation line along the [10T0] direction). Introducing a total dislocation into the graphite lattice is equivalent to inserting two extra planes of atoms (equivalent to one hexagon width, highlighted by the dashed rectangular box in Fig. 16) into the graphite lattice above the undeformed lattice. If a successive series of total dislocations are stacked along the $-c$ - direction to form a dislocation wall, a tilt boundary, which bends the graphite lattice is established. This boundary forms a $40^{\circ} 18^{\prime}\left(2 * \tan ^{-1}\left(a / 2 c_{0}\right)\right.$ tilt angle about the $<01 \mathrm{~T} 0>$ axis, and it is a twinning boundary with a (2П12) habit plane. A $40^{\circ} 18^{\prime}$ coherent twin boundary was observed in a graphite nodule from ductile iron but it was never analyzed [20]. Fig. 17 is a geometric construction for this $40^{\circ} 18^{\prime}$ twinning boundary.

A total dislocation in graphite can dissociate as two partial dislocations according to the following equation [21-22]:

$$
\frac{1}{3} a[2 \overline{1} \overline{1} 0]=\frac{1}{3} a[10 \overline{1} 0]+\frac{1}{3} a[1 \overline{1} 00]
$$

where, $\frac{1}{3} a[10 \mathrm{~T} 0]$ and $\frac{1}{3} a[1 \mathrm{~T} 00]$ are the two partial dislocations at 60-degree angle.

Each of the partial dislocations is equivalent to inserting an extra half hexagon width (one atom plane) into the lattice. The dissociated partials can be separated by a shear stress 
along the $\langle 10 \mathrm{~T} 0\rangle$ directions [23]. Moreover, a partial dislocation changes the stacking sequence of the basal planes, which will be discussed in the following sections.

For the purposes of this discussion, the partial dislocation with Burgers vector $\frac{1}{3} a\left[10\right.$ T0] will be designated as Partial $1,\left(\overrightarrow{P_{1}}\right)$, and the partial with Burgers vector $\frac{1}{3} a$ [1T00] designated as Partial 2, $\left(\overrightarrow{P_{2}}\right)$. This dissociation allows the system to possess a lower energy since the two extra half planes can be separated to produce less lattice distortion. For example, if alternating $\overrightarrow{P_{1}}$ and $\overrightarrow{P_{2}}$ partial dislocations are stacked along the $-c$ - direction at a dislocation wall, a twinning boundary of $20^{\circ} 48^{\prime}$ tilt about the $<01$ T0 $>$ axis (with a (2TI) habit plane) [21-23,27] is formed. This twining boundary has been widely reported in natural and synthetic graphite [21-23], as schematically illustrated in Fig. 18. Other possible tilt angles for twin/tilt boundaries have also been observed by Theuwissen et al using Automated Crystal Orientation Mapping [19].

It should be clarified that Burgers vectors for the dislocations discussed in section 6.3 are in the basal planes, and they do not have c-direction components. It should be noted that the dislocation discussed here is different from a stacking fault, which has a c-axis Burgers vector component.

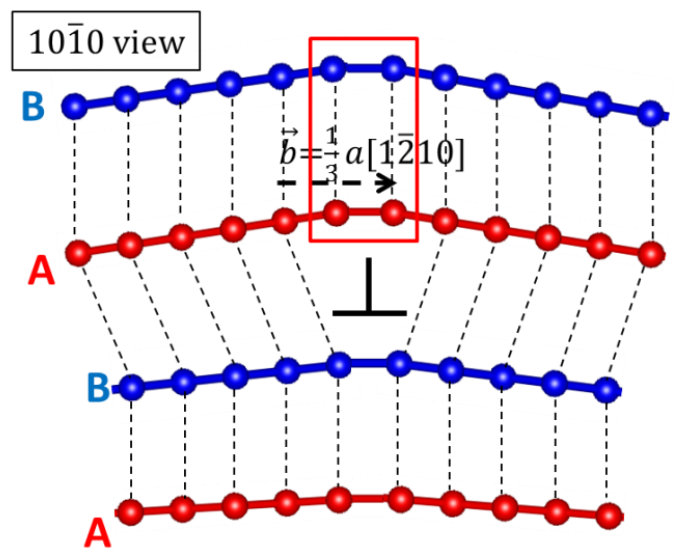

Fig. 16. Schematic for the graphite lattice with a total dislocation of $\vec{b}=\frac{1}{3} a$ [1210]. The lattice next to this edge dislocation is distorted. 


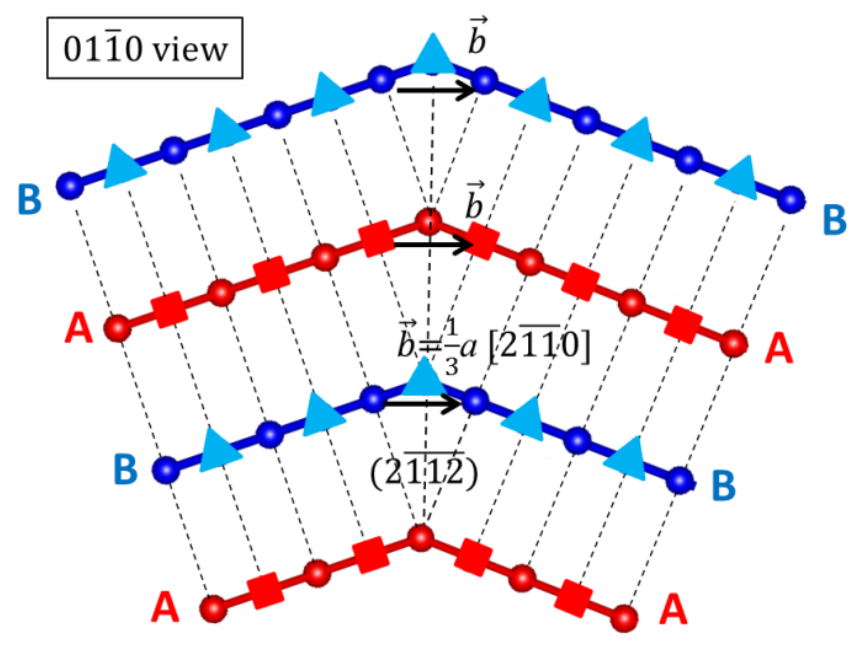

Fig. 17. A twining boundary with a (2П1) habit plane tilts the basal plane for $40^{\circ} 18^{\prime}$ around $<01$ T0 $>$ axis. $\bigcirc$ : in plane of drawing; $\square: a \sqrt{3} / 6$ in front of plane of drawing; $\triangle$ : $a \sqrt{3} / 6$ behind plane of drawing.

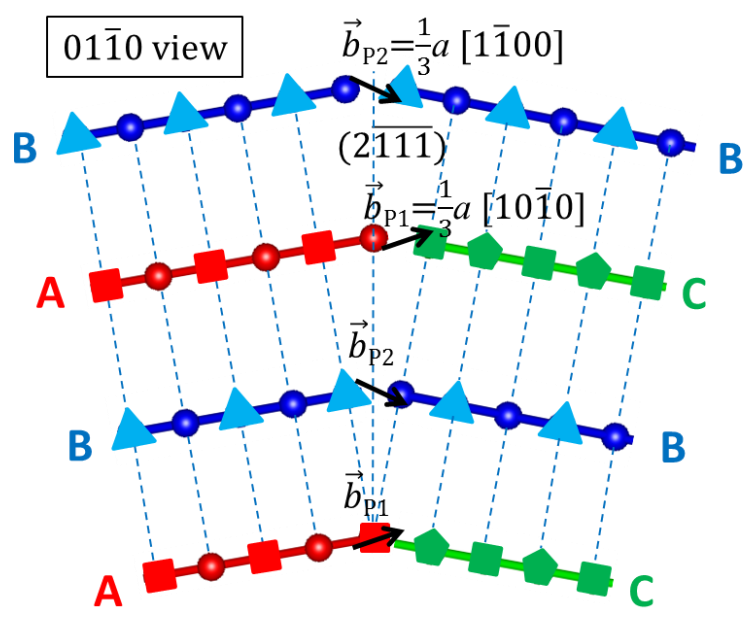

Fig. 18. A twining boundary with a (2Tा) habit plane and a $20^{\circ} 48^{\prime}$ tilt angle about the $<01$ T0 $>$ axis is composed of successively alternating partial dislocation in every basal plane, constructed after Freise and Kelly [22]. $\bigcirc$ : in plane of drawing; $\square: a \sqrt{3} / 6$ in front of plane of drawing; $\triangle: a \sqrt{3} / 6$ behind plane of drawing; $\triangle: a \sqrt{3} / 6$ behind the plane of drawing.

\subsection{H/3R Structure Transition}

6.4.1 2H/3R Structure Transition by Partial Dislocations. Based on section 2, the translation vector for linking the $\mathrm{A}, \mathrm{B}$ and $\mathrm{C}$ positions in the graphite lattice is equivalent 
to a partial dislocation, as illustrated in Fig. 19 and Table 1. It can be seen that introducing a partial dislocation can change the stacking sequence of the basal planes, but introducing a total dislocation cannot. Table 1 summarizes the resulting stacking sequence when a lattice is sheared with either a partial dislocation or a total dislocation. It can be noticed from Table 1 that the partial dislocations may incorporate the $\mathrm{C}$ layers in an $\mathrm{ABAB} \ldots$ hexagonal structure and form an $\mathrm{ABCABC} \ldots$ rhombohedral structure. If a series of partial dislocations are introduced to a lattice of $\mathrm{ABABABAB}$... sequence, the resultant stacking sequence would be different accordingly to the order of the partial dislocations: a final stacking sequence of $\mathrm{CBCBCBCB} \ldots$ is produced by introducing alternating $\overrightarrow{P_{1}}$ and $\overrightarrow{P_{2}}$ in the basal planes; (2) a final stacking sequence of CABCABCA... is produced by adding $\overrightarrow{P_{1}}$ in alternating basal planes. In the case of $\mathrm{CBCBCBCB...,} \mathrm{it}$ was still a hexagonal structure. In the other case, continuous rhombohedral structure was created by introducing the same partial dislocations to alternating basal planes. Moreover, introducing a series of dislocations to the basal planes would distort the graphite lattice, by forming a tilt boundary. Fig. 20 is a geometric construction of the graphite lattice with the same partial dislocations in alternating basal planes. The two boundaries shown in Fig. 20 were actually dissociated from a twinning boundary as shown in Fig. 18. Assuming that the boundary on the left is made of $\overrightarrow{P_{1}}$ in alternating basal planes and the boundary on the right is made of $\overrightarrow{P_{2}}$ in alternating basal planes, two equal tilt angles about the $<01 \mathrm{~T} 0>$ axes are produced at the two boundaries. A tilt angle of $10^{\circ} 24^{\prime}\left(\tan ^{-1}\left(a / 4 c_{0}\right)\right)$ about the $\langle 01 \mathrm{~T} 0\rangle$ axis is shown at the tilt boundary on the left in Fig. 20. At the same time, the left tilt boundary separated a region of $2 \mathrm{H}$ structure and a region of $3 \mathrm{R}$ structure. Similarly, the $3 \mathrm{R}$ structure is separated from the $2 \mathrm{H}$ structure by the other $10^{\circ} 24^{\prime}$ tilt boundary on the right side in Fig. 20.

Experimental evidence for the $10^{\circ} 24^{\prime}$ tilt boundary about $\langle 01 \mathrm{~T} 0\rangle$ axis was confirmed in the present study, when the same $2 \mathrm{H} / 3 \mathrm{R}$ boundary as in Fig. 14 was titled to a $<01 \mathrm{~T} 0>$ beam direction. The measured tilt boundary on $<01 \mathrm{~T} 0>$ SADs was $\sim 11$ degrees as shown in Fig. 21, which closely matches the tilt angle in Fig. 20. However, crystal structure change (2H to $3 \mathrm{R}$ ) across this boundary was only diffrentiable on their $\angle \mathrm{T} 2 \mathrm{~T} 0>\mathrm{SAD}$ patterns as given in Fig. 14. 


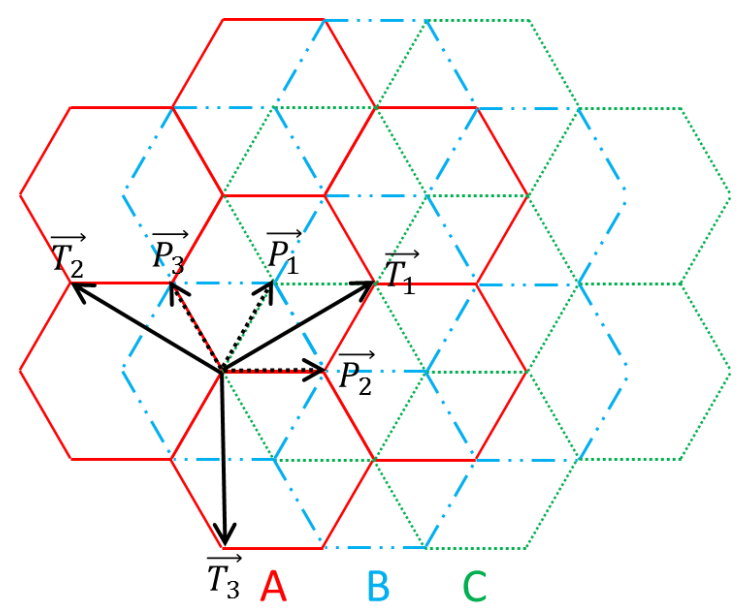

Fig. 19. Partial dislocations $\left(\overrightarrow{P_{1}}, \overrightarrow{P_{2}}\right.$ and $\left.\overrightarrow{P_{3}}\right)$ and total dislocations $\left(\left(\overrightarrow{T_{1}}, \overrightarrow{T_{2}}\right.\right.$ and $\left.\overrightarrow{T_{3}}\right)$ in graphite. A total dislocation is made of two partial dislocations: $\overrightarrow{T_{1}}=\overrightarrow{a_{1}}=\overrightarrow{P_{1}}+\overrightarrow{P_{2}}$, and $\overrightarrow{T_{2}}=\overrightarrow{a_{2}}=\overrightarrow{P_{3}}-\overrightarrow{P_{2}}$, and $\overrightarrow{T_{3}}=\overrightarrow{a_{3}}=-\overrightarrow{P_{1}}-\overrightarrow{P_{3}}$. Angles between $\overrightarrow{P_{1}}$ and $\overrightarrow{P_{2}}$, and between $\overrightarrow{P_{1}}$ and $\overrightarrow{P_{3}}$, are both 60 degrees.

Table 1. Examples of changing stacking sequences by introducing partial dislocations to the graphite lattice. A total dislocation does not change the stacking sequence.

\begin{tabular}{cccc}
\hline Introduced Dislocation & $\overrightarrow{P_{1}}$ & $\overrightarrow{P_{2}}$ & $\overrightarrow{T_{1}} / \overrightarrow{T_{2}} / \overrightarrow{T_{3}}$ \\
\hline \multirow{2}{*}{ Stacking Sequence Change } & $A \rightarrow C$ & $A \rightarrow B$ & $A \rightarrow A$ \\
& $B \rightarrow A$ & $B \rightarrow C$ & $B \rightarrow B$ \\
& $C \rightarrow B$ & $C \rightarrow A$ & $C \rightarrow C$ \\
\hline
\end{tabular}




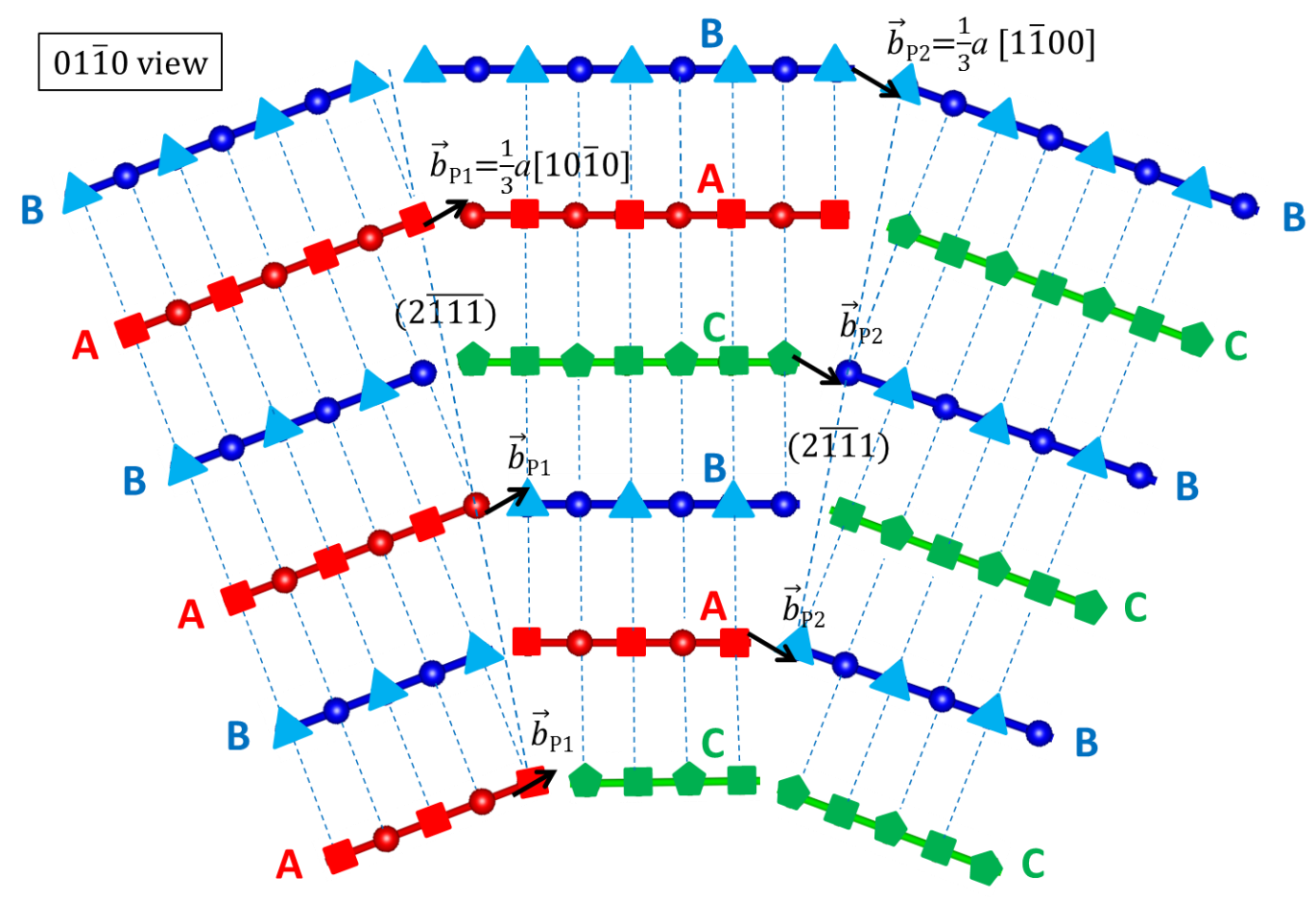

Fig. 20. Partial dislocations in alternating basal planes produced a region of $3 R$ structure in between the $2 \mathrm{H}$ structures, and two tilt angles of $10^{\circ} 24^{\prime}$ about the $\left.<01 \mathrm{~T} 0\right\rangle$ axis were created. $\bigcirc$ : in the plane of drawing; $\square: a \sqrt{3} / 6$ behind the plane of drawing; $\triangle: a \sqrt{3} / 6$ in front of the plane of drawing; $\triangle: a \sqrt{3} / 6$ behind the plane of drawing [2223].

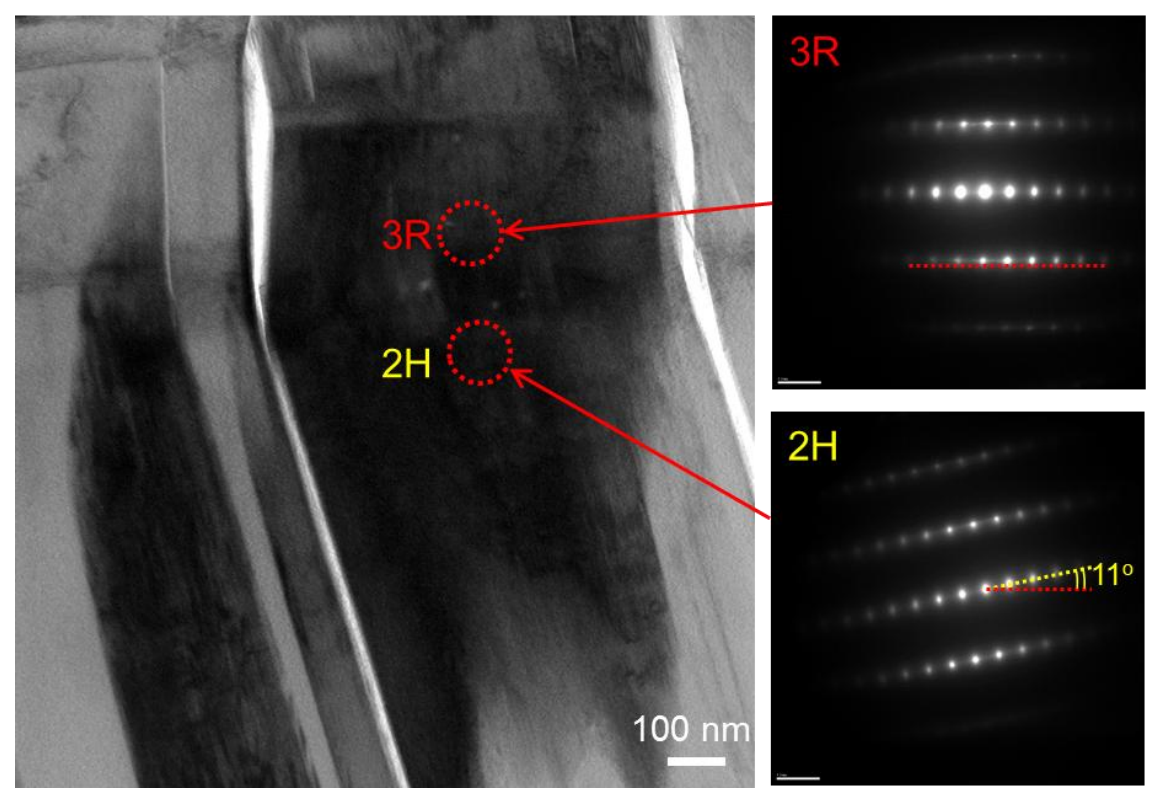

Fig. 21. $<01 \mathrm{~T} 0>$ SAD patterns for the adjacent grains in Fig. 14. The tilt angle measured between two grains was about 11 degrees along their $<01$ T0 $>$ zone axes. 
6.4.2 2H/3R Structure Transition by Stacking Faults . Introduction of a stacking fault in graphite lattice may produce a transition from $2 \mathrm{H}$ to $3 \mathrm{R}[10-12,21,25]$. Examples of several stacking faults are schematically illustrated in Fig. 22: (a) a basal slip (Shockley partial dislocation), (b) a vacancy loop (Frank dislocation) or (c) an interstitial prismatic loop (Frank dislocation). Basal slip [25] is a basal dislocation (Burgers vector in the basal plane), which is formed by shearing the carbon hexagonal lattice following partial dislocations without breaking C-C bonds. Transition of basal plane stacking sequence at a boundary has been experimentally observed in a bi-layer graphene material, and the associated defect was a basal slip dislocation [26]. A vacancy loop is formed by removing "extra-half" plane from the graphite lattice; an interstitial prismatic loop can be simplified as insertion of "extra-half" plane into the graphite lattice. A vacancy loop and a prismatic loop are non-basal dislocations because of the c-axis component in the Burgers vector.

According to Delavignette and Amelinckx [25], a dislocation with Burgers vector having a component in the c-direction and emerging in the basal plane will give rise to spiral growth on basal plane. Spiral growth is important in regard to growth and formation of spheroidal graphite, since many theories include spheroidal graphite growth being associated with this mechanism [15, 28]. However, the defects observed in the present work cannot explain a growth mechanism based on the graphite rotation growth around screw dislocations.

Insertion of "extra-half" plane in the graphite lattice were frequently observed in the study presented here and several further examples are shown in Fig. 23. It is straightforward that the ABC/ACB stacking sequence can be created by inserting an "extra-half" plane of C-position (a partial dislocation is incorporated) into the ABAB... lattice for an interstitial loop. However, directly removing an "extra-half" plane will lead to unstable AA or BB structure. Therefore, a vacancy loop is normally associated with a partial dislocation at its periphery in order to eliminate the unstable structure (see Fig. 22(b)). A defect like this will be thin enough to produce streaking of basal reflections in the SADPs. Circular and hexagonal loops have been observed in natural and synthetic graphite [25]. It has been proposed that a partial dislocation enclosed a faulted region of rhombohedral $(3 \mathrm{R})$ structure in a hexagonal $(2 \mathrm{H})$ parent lattice in the literature $[21,25]$, 
where visible dissociated ribbons /dislocation loops were present in the graphite lattice $[10,25]$.
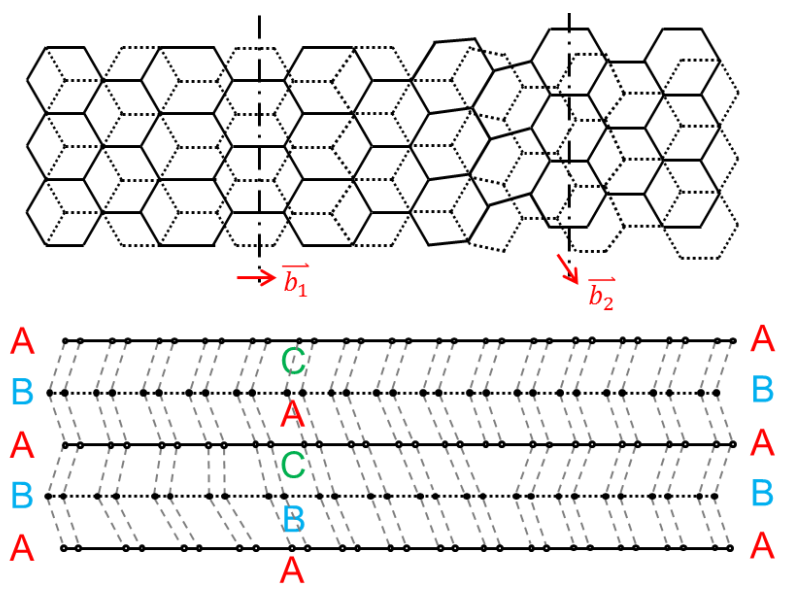

(a)

\begin{tabular}{c:cc:c}
$\mathrm{A}$ & $\mathrm{B}$ & $\mathrm{A}$ \\
\hline $\mathrm{B}$ & $\mathrm{A}$ & $\mathrm{B}$ \\
\hline $\mathrm{A}$ & $\mathrm{C}$ & $\mathrm{A}$ & $\mathrm{B}$ \\
\hline $\mathrm{B}$ & $\mathrm{A}$ & $\mathrm{b}$ & $\mathrm{A}$ \\
\hline $\mathrm{A}$ & $\mathrm{B}$ & $\mathrm{B}$ \\
\hline $\mathrm{B}$ & $\mathrm{A}$ & $\mathrm{A}$ \\
\hline $\mathrm{A}$ & &
\end{tabular}

(b)

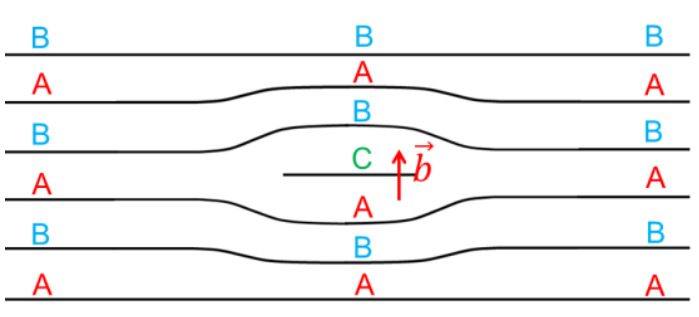

(c)

Fig. 22. Schematics for (a) a basal slip, (b) a vancancy loop and (b) an interstitial prismatic loop in graphite lattice (reconstructed after reference 25). Vector $\vec{b}$ is the Burgers vector.

Basal plane distortion (e.g. bending) is observed near a stacking fault, thus a stacking fault is beneficial in regard of curvature accommodation in a nodule. Meanwhile, a stacking fault locally (in few basal planes) alters the stacking sequence of graphite lattice. Large number of randomly distributed stacking faults (e.g. mixture of vacancy loop and interstitial loop) may alter the graphite stacking sequence frequently however they may not produce an overall net curvature to graphite lattice, which may offer an explanation for the observations in Fig. 13, where the c-axes of the $2 \mathrm{H}$ structure and the $3 \mathrm{R}$ structure were parallel. 


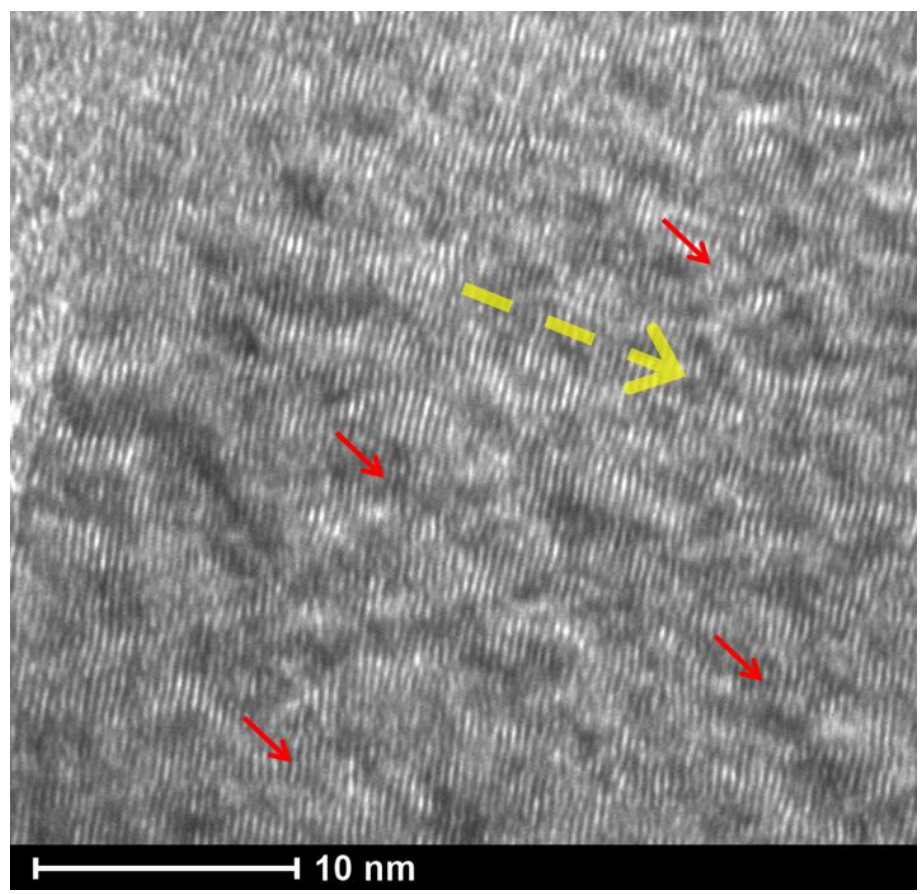

Fig. 23. Stacking faults in the graphite lattice, indicated by the arrows in the high resolution image. Center direction of graphite nodule is indicated by dashed arrow.

It should be noted that a low stacking fault energy promotes formation of stacking faults in graphite. In this case, areas of rhombohedral structure could form in the hexagonal structure. The calculated stacking fault energy for graphite was small (0.0005$0.0007 \mathrm{~J} / \mathrm{m}^{2}$ ) thus a stacking fault has a high probability to occur in graphite $[21,24]$. The separation distance between the two boundaries of a faulted region was determined to be $\sim 80 \mathrm{~nm}$ in the natural graphite [10]. Such a small distance is even smaller than the smallest SAD aperture size $(150 \mathrm{~nm})$ for the TEM used in this study. The observation of $2 \mathrm{H}$ and $3 \mathrm{R}$ mixture in a graphite grain may result from the small-sized faulted areas and a high density of stacking faults in the spheroidal graphite particle.

6.4.3 2H/3R Structure Transition by $c$-axis Rotation Faults. Fig. 10 implies the existence of c-axis rotation faults in the nodule. A $c$-axis rotation fault in graphite can be simplified as rotating a second graphene layer relative to the first graphene layer for certain angles. The occurrence of $c$-axis rotation faults have been verified in the flake graphite particles in graphitic nickel [29-31] and cast irons [32-33].

Many papers have claimed that the $c$-axis rotation faults were able to change the stacking sequence of the graphene layers [34-38], as illustrated in Fig. 24 [35]. These 
variant local stacking sequences due to $c$-axis rotation faults also explain the occurrence of $2 \mathrm{H}$ and $3 \mathrm{R}$ mixture in the graphite specimen studied. Moreover, rotation faults created more steps required for growth of crystal faces. As a result, kinetics of carbon accretion/graphite growth was promoted [39-40].

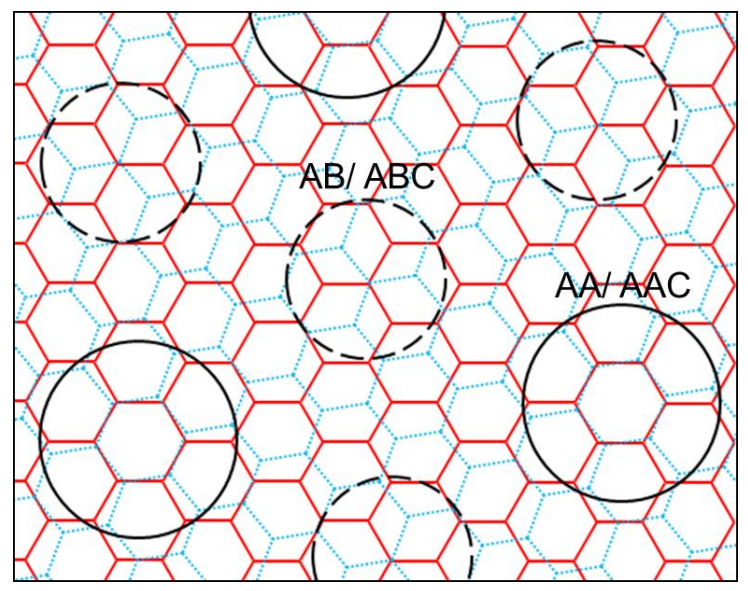

Fig. 24. c-axis rotation faults induced different local stacking sequence changes in graphite lattice [35]. The rotation angle between the graphene layers is $\sim 9.3$ degree.

\subsection{Curvature Accommodation by Tilt Boundaries and Twinning Boundaries} During the intermediate stage of growth, the curvature of a nodule is formed by tilt boundaries. A tilt boundary with a 11-degree tilt angle about the $<01 \mathrm{~T} 0>$ axis was characterized in the nodule (see Fig 20).

In theory, a series of dislocations with varying Burgers vectors are able to tilt the basal planes at varying angles, as long as the atomic arrangements on both sides of the boundary do not violate the stacking sequences required for the basal planes. It has been reported that a semicoherent $[39,41]$ boundary can have any tilt angle. However, matrix and twinned basal planes are at specific angle for a coherent twinning boundary, i.e., a coherent twin boundary has its specific tilt angle (the angle measured between parent and twin c-axes when viewed parallel to the twin boundary and the basal planes) between their c-axes. Examples are the twinning boundaries of $20^{\circ} 48^{\prime}$ and $40^{\circ} 18^{\prime}$ tilt angles, as shown in Fig. 17 and Fig. 18. 
The introduction of c-axis rotation boundaries between the grains within a single column will start to open up the inter-columnar boundary since simple tilt boundaries will be more difficult to maintain out of the plane of the columnar boundary.

\section{CONCLUSIONS AND FUTURE WORK}

The structure of graphite nodules in ductile iron were found to be dependent on the growth stages of the nodule, which might result from the growth mechanism changes from early stage to later stage. Curved graphene layers with gradual and continuous changes of the basal plane directions were observed in a graphite nodule retained at its early growth stage, and in the area formed at the early growth stages in another graphite nodule. Thin layered stacking faults give rise to streaking in the basal reflections, which give rise to curvature of the nodule and growth steps on the surface. Radially distributed columnar substructures separated by basal plane tilt boundaries were observed at the outside part of the graphite nodule, which were formed during intermediate growth stages. Sharp transitions of the basal plane orientations were observed across the tilt boundaries. Each columnar substructure consisted of many peripheral subgrains, with parallel $c$-axis direction for all subgrains in a columnar substructure. The subgrains in a columnar substructure are separated by c-axis rotation faults, but the exact nature of the fault was not identified in this study.

$<1120>$ SAD patterns were used to characterize the crystal structure of graphite. The crystal structures of the graphite nodules in ductile iron included both the hexagonal $(2 \mathrm{H})$ structure and the rhombohedral (3R) structure. The orientations of both structures were well-defined in the spheroidal graphite particles studied. 2H-3R structure transitions were achieved either by introducing the same partial dislocations in alternating basal planes to a $2 \mathrm{H}$ structure, or by forming stacking faults in the graphite lattice. Twining boundaries and tilt boundaries were able to introduce curvature to the graphite lattice.

Identification of region with only the $2 \mathrm{H}$ structure or the $3 \mathrm{R}$ structure was not successful either using the SAD pattern or the CBED pattern. This merits further high resolution studies in future work. Structures of the graphite formed at late growth stages in a spheroidal graphite particle will be included in future studies. TEM examination of 
the unquenched spheroidal graphite particles will be conducted in the future, which will be compared to the present study where the samples were quenched.

\section{ACKNOWLEDGEMENT}

The authors would like to gratefully thank Dr. Jessica Terbush and Dr. Clarissa Wisner for their mentoring on HRSEM, FIB and HRTEM operations. Dr. Scott Miller is recognized for his guidance on the SAD pattern simulations. Dr. Mingzhi Xu is gratefully acknowledged for his help with designing and preparing samplers, and melting ductile irons. The authors also wish to thank Marc Harris, Daniel Field, Seth Rummel, Joe Govro, Terrell Webb and Mark Emmendorfer for their assistances on quenching experiments. The FEI Helios NanoLab dual beam FIB was obtained with a Major Research Instrumentation grant from the National Science Foundation under contract DMR-0723128 and the FEI Tecnai F20 scanning/transmission electron microscope was obtained with a Major Research Instrumentation grant from NSF under contract DMR0922851.

\section{REFERENCES}

[1] J. Qing, V.L. Richards and D.C. Van Aken, "Examination of Nodular Graphite Formation and Austenite Solidification in Ductile Iron", Transactions of American Foundry Society, Paper 15-072, 2016.

[2] J. Qing, V. L. Richards and D.C. Van Aken, "Examination of Spheroidal Graphite Growth and Austenite Solidification in Ductile Iron”, Metall. And Mat. Trans. A, Vol 47, Issue 12, pp.6197-6213, 2016.

[3] Accepted by 2017 Transactions of American Foundry Society, J. Qing, V. L. Richards and D.C. Van Aken, "Staged Growth of Spheroidal Graphite in Ductile Irons".

[4] D. D Double and A. Hellawell, "Growth Structure of Various Forms of Graphite," in The Metallurgy of Cast Iron: Proceedings of the Second International Symposium on the Metallurgy of Cast Iron, Geneva, Switzerland, Georgi Publishing, pp. 509-28, 1974. 
[5] H. O. Pierson, in Handbook of Carbon, Graphite, Diamond and Fullerenes: Properties, Processing, and Applications, Park Ridge (NJ): Noyes, 1993.

[6] B. Xu, M. S. Su, G. Liu and C. Y. Ouyang, "Understanding the Effect of the Layer-to-layer Distance on Li-Intercalated Graphite," J. Appl. Phys., Vol 111, 124325, 2012.

[7] R. E. Franklin, "The Structure of Graphitic Carbons," Acta Crystallographica, Vol 4, pp.253-61, 1951.

[8] R. W.G. Wyckoff, in Crystal Structures, John Wiley, New York, pp. 9-45, 1963.

[9] Q. Lin, T. Lin, Z. Liu, Y. Song, L. He, Z. Hu. Q. Guo and H. Ye, "Highresolution TEM Observations of Isolated Rhombohedral Crystallites in Graphite Blocks," Carbon, Vol 50, pp. 2369 -71, 2012.

[10] P. Delavignette and S. Amelinckx, "Dislocation Ribbons and Stacking Faults in Graphite," Journal of Applied Physics, Vol 31, pp.1691-2, 1960.

[11] P. Delavignette and S. Amelinckx, "Dislocation Pattern in Graphite," Journal of Nuclear Materials, Vol 5, pp.17-66, 1962.

[12] S. Amelinckx and P. Delavignette, "Electron Optical Study of Basal Dislocations in Graphite," Journal of Applied Physics, Vol 31, pp.2126-35, 1960.

[13] E. Matuyama, Nature, Vol 178, pp.1459-60, 1956.

[14] H. P. Boehm and U. Hofmann, "Die Rhomboedrische Modifiaktion des Graphits," Zeitschrift Für Anorganische und Allgemeine Chemie, Vol 278, Issue 1-2, pages 58-77, 1955.

[15] J. P. Sadocha and J. E. Gruzleski, "The Mechanism of Graphite Spheroid Formation in Pure $\mathrm{Fe}-\mathrm{C}-\mathrm{Si}$ alloys," in The Metallurgy of Cast Iron: Proceedings of the Second International Symposium on the Metallurgy of Cast Iron, Geneva, Switzerland, Georgi Publishing, pp. 443-56, 1974.

[16] S. Amini and R. Abbaschian, "Nucleation and Growth Kinetics of Graphene Layers from a Molten Phase", Carbon, Vol 51, pp. 110-123, 2013.

[17] B. Miao, D. O. North Wood, W. Bian, K. Fang and M. H. Fan, "Structure and Growth of Platelets in Graphite Spherulites in Cast Iron," Journal of Materials Science, Vol 29, pp. 255-61, 1994. 
[18] B. Miao, K. Fang and W. Bian, "On the Microstructure of Graphite Spherulites in Cast Irons by TEM and HREM,” Acta Metal. Mater., Vol 38, pp. 2167-74, 1990.

[19] K. Theuwissen, J. Lacaze, L. Laffont, "Structure of graphite precipitates in cast iron," Carbon, Vol 96, pp. 1120-8, 2016.

[20] J. P. Monchoux, C. Verdu, G. Thollet, R. Fougères and A. Reynaud, "Morphological Changes of Graphite Spheroids during Heat Treatment of Ductile Cast Irons," Acta Mater., Vol 49, pp. 4355-62, 2001.

[21] B.T. Kelly, in Physics of Graphite, Allied Science Publisher, London, pp.34-40, 1981.

[22] E. J. Freise and A. Kelly, "Twinning in Graphite," Proceedings of Royal Society of London, Series A, Mathematical and Physical Science, Vol. 264, pp.269-76, 1961.

[23] C. Baker, L. M. Gillin and A. Kelly, "Twinning in graphite," Second Conference on Industrial Carbon and Graphite, Society of Chemical Industry, London, pp. 132-8, 1966.

[24] M. Heerschap, P. Delavignette and S. Amelyncks, "Electron Microscope Study of Interlamellar Compounds of Graphite with Bromine, Iodine Monochloride and Ferric Chloride," Carbon, Vol 1, pp. 235-8, 1964.

[25] S. Amelinckx. P. Delavignette and M. Heerschap, "Dislocation and Stacking Faults in Graphite," in Chemistry and Physics of Carbon, edited by Philip L. Walker, Vol 1, pp.1-77,1966.

[26] B. Butz, C. Dolle, F. Niekiel, K. Weber and D. Waldmann, "Dislocations in bilayer graphene", Nature, Vol. 505, Issue 7484, pp.533-7, 2014.

[27] E. J. Freise and A. Kelly, "The Deformation of Graphite Crystals and the Production of the Rhombohedral Form," Philosophical Magazine, Vol 8, Issue 93, pp.1519-33, 1963.

[28] I. Minkoff, "The Spherulitic Growth of Graphite Crystal," Materials Research Society Symposium Proceedings, Vol 34, pp. 37-45, 1985.

[29] D. D Double and A. Hellawell, "Defects in Eutectic Flake Graphite," Acta Metallurgica, Vol 19, Issue 12, pp. 1303-6, 1971. 
[30] D. D Double and A. Hellawell, "The Structure of Flake Graphite in Ni-C Alloy," Acta Metallurgica, Vol 17, Issue 8, pp. 1071-83, 1969.

[31] D. D Double and A. Hellawell, "The Nucleation and Growth of Graphite- the Modification of Cast Iron," Acta Metall. Mater., Vol 43, pp. 2435-42, 1995.

[32] G. Purdy and M. Audier, “Electron Microscopical Observations of Graphite In Cast Irons", The Physical Metallurgy of Cast Iron, John Wiley and Sons, pp. 1323, 1983.

[33] J. Park and Y. Lee, "Study on the Stacking Faults in Eutectic Flake Graphite Commercial Gray Cast Iron”, J. of the Kotean Inst. Of Met. \& Mater. , Vol 32, No.9, pp. 1103-6, 1994.

[34] P. Zhu, R. Sha and Y. Li, "Effect of Twin/Tilt on the Growth of Graphite," Materials Research Society Symposia Proceedings, Vol 34, pp. 3, 1984

[35] J. M. Campanera, G. Savini, I. Suarez-Martinez and M. I. Heggie, "Density Functional Calculaitons on the Intricacies of Moiré Patterns on Graphite," Physical Review B, Vol 75, 235449, 2007.

[36] V. J. Cee, D. L. Patrick and T. P. Beebe Jr., "Unusual Aspects of Superperiodic Features on Highly Oriented Pyrolytic Graphite," Surface Science, Vol 329, pp.141-8, 1995.

[37] M. Oron and I. Minkoff, "Growth Twining in Graphite Dendrites," Phil. Mag., Vol 9, pp.1059-62, 1964.

[38] I. Minkoff and S. Myron, "Rotation Boundaries and Crystal Growth in the Hexagonal System," Philosophical Magazine, Vol 19, pp. 379-87, 1969.

[39] I. Minkoff, The Physical Metallurgy of Cast Iron, John Wiley and Sons, pp. 37-45, 1983.

[40] I. Minkoff and B. Lux, "Graphite Growth from Metallic Solution," in The Metallurgy of Cast Iron: Proceedings of the Second International Symposium on the Metallurgy of Cast Iron, Geneva, Switzerland, Georgi Publishing, pp. 473-93, 1974.

[41] W. Bollman and B. Lux, "Grain Boundaries in Graphite," in The Metallurgy of Cast Iron: Proceedings of the Second International Symposium on the Metallurgy of Cast Iron, Geneva, Switzerland, Georgi Publishing, pp. 461-71, 1974. 